Department for Innovation, Universities \& Skills

\title{
Gender Gaps in
}

Higher Education

Participation

An Analysis of the Relationship

between Prior Attainment and

Young Participation by Gender,

Socio-Economic Class and Ethnicity

Stijn Broecke and Joseph Hamed

Higher Education Analysis

Department for Innovation, Universities and Skills

DIUS Research Report 0814 


\title{
Gender Gaps in Higher Education Participation
}

\author{
An Analysis of the Relationship between Prior \\ Attainment and Young Participation by Gender, \\ Socio-Economic Class and Ethnicity
}

Stijn Broecke and Joseph Hamed

Higher Education Analysis

Department for Innovation, Universities and Skills

DIUS Research Report 08-14

(C) Crown Copyright 2008

The views expressed in this report are the authors' and do not necessarily reflect those of the Department for Innovation, Universities and Skills 


\section{Acknowledgments}

We would like to thank John Thompson (HEFCE), Mark Corver (HEFCE), Anna Vignoles (IoE), Arnaud Chevalier (Royal Holloway University), and analysts at DCSF for comments on earlier drafts of this paper. We are also very grateful to the YCS team at DCSF (and Clare Baker in particular) for their assistance with the YCS. Any remaining errors are, of course, entirely our own. 


\section{Summary}

- Historically, women had been under-represented in Higher Education. By 1992, however, the Age Participation Index suggested that young women's participation rates in England had caught up with those of men. The 2005/06 Higher Education Initial Participation Rate figures for 17-30 year olds showed a 7.2 percentage participation gap, in favour of women - a gap which appears to continue to widen.

- This gender gap does not appear at the point of entry to Higher Education, and can be observed early on in the educational system. In $2007,65 \%$ of girls achieved $5+$ A*-C GCSEs or equivalent, compared to $55.8 \%$ of boys. Girls are also more likely to stay on in full-time education at age 16 ( $82 \%$ of girls and $72 \%$ of boys). They are more likely to be entered for A levels, more likely to pass them, and also more likely to do better (achieve an A grade) than boys.

- In this paper, we use two new datasets to explore the extent to which the gender gap in HE participation amongst young people in England is related to prior attainment. The first dataset is Cohort 12 of the Youth Cohort Study - a longitudinal survey of young people aged 16 and upwards which monitor their decisions and behaviour in making the transition from compulsory education to Further or Higher Education, or to the labour market. The second dataset consists of recently matched schools and higher education administrative records (the National Pupil Database, the Pupil Level Annual Schools Census, and the Higher Education Statistics Agency student record).

- For young people (18-19 year olds) who are English-domiciled and who did not attend an independent school in Year 11, we find no conclusive evidence of a gender difference in the likelihood of participating in HE (excluding HE in FE) - once prior attainment (in the form of young people's attainment at GCSE or equivalent) is controlled for. This is not to say that the gender gap in HE participation does not exist, nor that it isn't large. But our analysis suggests that no additional gender effect appears at the point of entry to Higher Education and, hence, that efforts to reduce the gender gap in HE participation should predominantly be aimed at increasing the relative attainment of young men prior to $\mathrm{HE}$.

- In order to put the gender finding into perspective, we also replicated our analysis for: (i) young people from White backgrounds, compared to young people from ethnic minority backgrounds; and (ii) young people who were on Free School Meals in the last year of compulsory education, compared to those who weren't. We find that young people from ethnic minority backgrounds are overwhelmingly more likely to enter HE compared to White people with the same prior attainment. In the case of young people who were eligible for FSM, we find that prior attainment explains the vast majority of the gap in participation compared to non-FSM pupils, however we still find a small, negative (and statistically significant) effect, which we could not eliminate entirely in any of our models. In both cases (but particularly in the case of White in relation to ethnic minority students), this suggests that something else affects the likelihood to participate in $\mathrm{HE}$, over and above prior attainment. 


\section{Background}

1. Arguably, one of the greatest transformations to have occurred in English Higher Education (HE) over the past few decades has been the increased participation of women. For centuries, universities in England had been closed to women (Delamont 2006). England's two oldest universities (Oxford and Cambridge) did not fully admit women until 1920 and 1947, respectively ${ }^{1}$, and, on the eve of the Second World War, women constituted less than a quarter of the university student population (Dyhouse 2006). Yet, according to a well-known measure of participation in $\mathrm{HE}$ (the $\mathrm{API}^{2}$ ), women's participation rates had caught up with those of men by 1992:

Figure 1: Age Participation Index (API) by Gender, 1972-2000, and Higher Education Initial Participation Rate for 17-20 year olds (HEIPR20) for English domiciled first time participants in Higher Education courses at UK Higher Education Institutions and English, Welsh and Scottish Further Education Colleges, $1999 / 00$ to $2005 / 06$

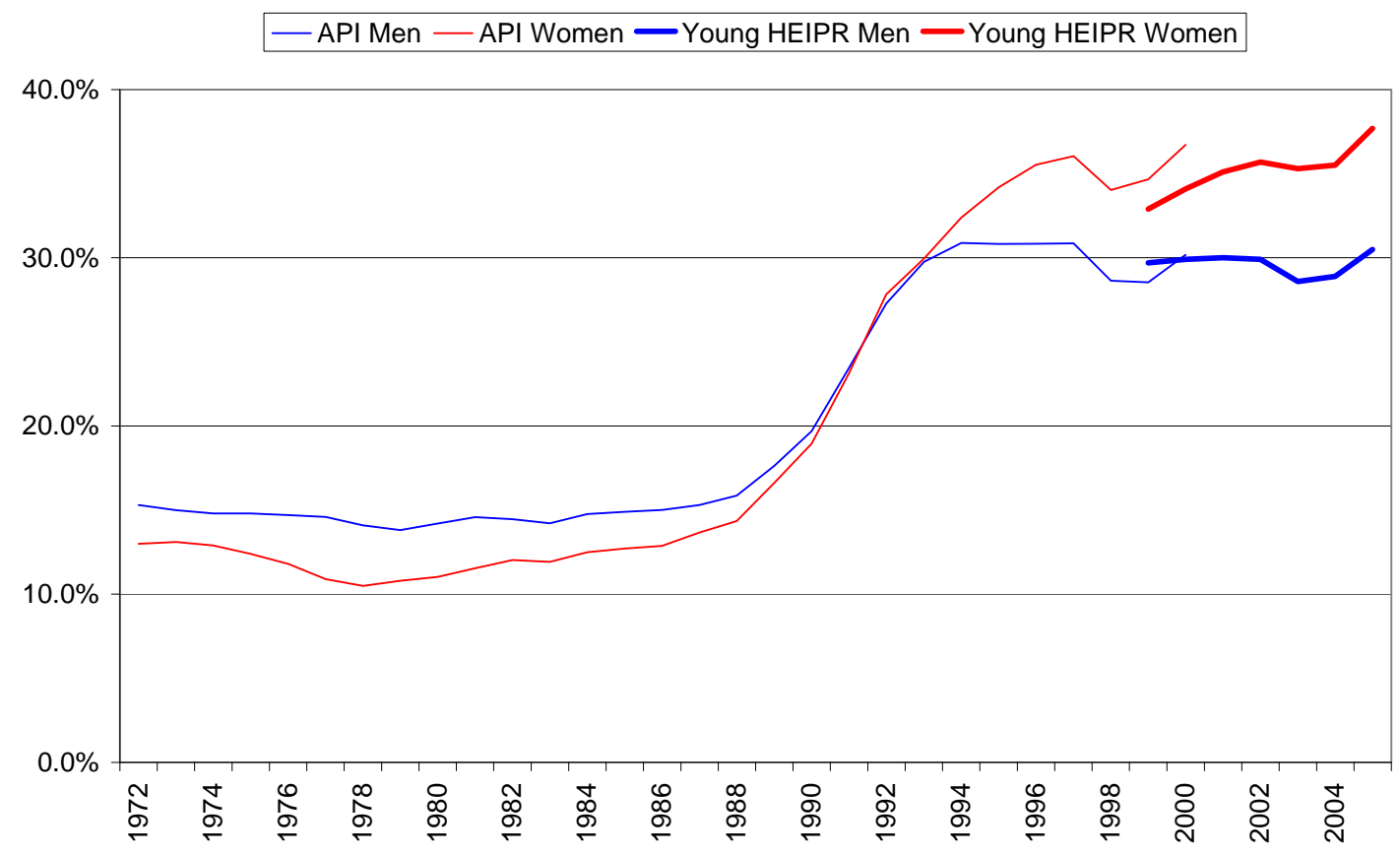

\footnotetext{
${ }^{1}$ In Oxford, it is only since 1920 that women have been eligible to be full members of the university and have been entitled to take degrees. In Cambridge, the first women students were examined in 1882, but attempts to make women full members of the university did not succeed until 1947.

${ }^{2}$ The Age Participation Index (API) is defined as the number of UK-domiciled young (aged less than 21) initial entrants to full-time and sandwich undergraduate courses of higher education, expressed as a proportion of the averaged 18 to 19 year old GB population. Further details can be obtained from Kelly and Cook (2007).
} 
2. The API was discontinued in 2001 and replaced by the Higher Education Initial Participation Rate (HEIPR) ${ }^{3}$, for which data is available since 1999. The short time series for which the HEIPR is available suggests that, over the recent past, the participation rate of women has continued to grow at a faster rate than that of men (see bold lines in Figure 1 above). In 2005/06, the probability that a seventeen year old male would participate in higher education by age 20 was estimated to be $30.5 \%$. For a seventeen year old female, this probability was estimated to be over seven percentage points higher, at $37.7 \%{ }^{4}$.

3. This gender "revolution" in HE is by no means unique to England. In Scotland, initial participation rates in $2005 / 06$ were $53.5 \%$ for females and $41.0 \%$ for males. ${ }^{5}$ In Wales, $22.6 \%$ of 18-19 year olds males were engaged in HE in 2004/05, compared to $30.3 \%$ of $18-19$ year olds females. ${ }^{6}$ In Northern Ireland, in $2005 / 06$, the male API was $40 \%$ and the female API was $56 \%{ }^{7}$ Higher female participation in HE is observed in most OECD countries, with the exception of Japan, Korea, Turkey, Germany and Mexico.

\footnotetext{
${ }^{3}$ The HEIPR is the National Statistic that the Government uses to measure progress in participation in relation to the Public Service Agreement target: by 2010, increase participation in higher education towards $50 \%$ of those aged 18 to 30 and also make significant progress year on year towards fair access, and bear down on rates of non-completion. It roughly equates to the probability that a seventeen year old will participate in higher education by age thirty given the age specific participation rates. The publication also provides a "young" HEIPR for 17-20 year olds, reproduced in Figure 1 above. For more information see: http://www.dfes.gov.uk/rsgateway/DB/SFR/s000716/SFR10_2007v1.pdf

${ }^{4}$ All comparisons of participation rates between men and women in this paper will be in terms of percentage point differences. We are aware that there are many different ways of comparing two percentages (see Gorard (1999) and Connolly (2006)). However, the conclusions reached in this paper are not altered by using the measures proposed by these authors.

${ }^{5}$ The Scottish Age Participation Index (API) for a given year is defined as the number of young Scots aged under 21 who enter a full-time HE course for the first time in that year taken as a percentage of the population of 17 year olds at 31 December in the same year. In simple terms it is an estimate of the share of 17 year olds in the population who, can be expected to enter HE for the first time before their 21st birthday, if current trends continue. For more information: http://www.scotland.gov.uk/Resource/Doc/179337/0051010.pdf

${ }^{6} \mathrm{http}: / / 194.81 .48 .132 /$ BusinessCommunity_Docs/W0708HE_circ.pdf

${ }^{7}$ The Northern Ireland Age Participation Index (API) is defined as the number of $\mathrm{NI}$-domiciled young entrants (aged under 21) to full-time undergraduate higher education (in the UK or Republic of Ireland) as a percentage of the 18 year-old population of Northern Ireland.
} 
Figure 2: Entry rates into tertiary-type A education and age distribution of new entrants (2005) in the OECD (sum of net entry rate for each year of age, by gender and mode of participation)

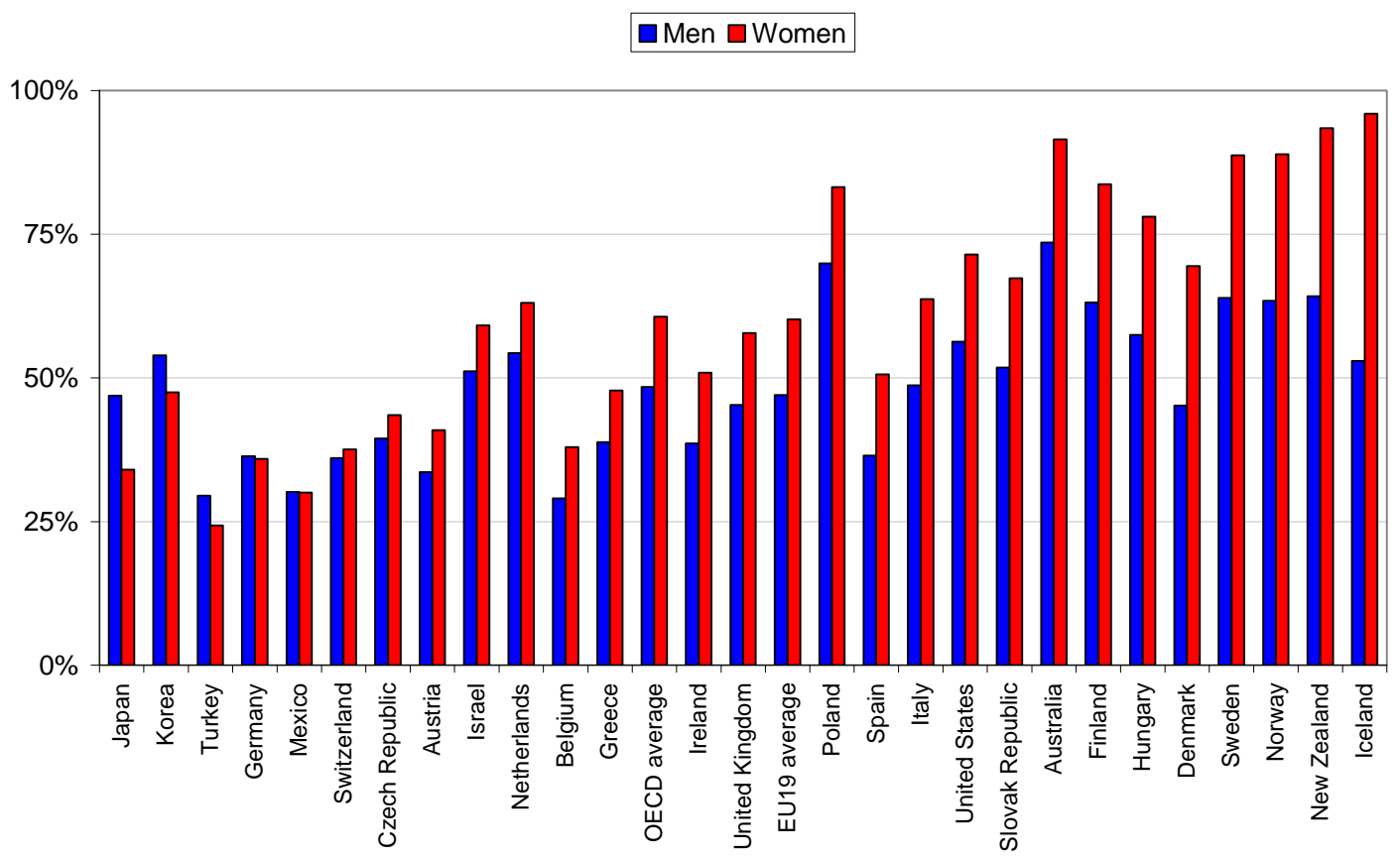

Source: OECD Education at a Glance 2007, Table C2.4.

Note: Mismatches between the coverage of the population data and the student/graduate data mean that the participation rates for those countries that are next exporters of students may be underestimated and those that are net importers may be overestimated.

4. Nor is this gender gap unique to Higher Education. The Department for Children, Schools and Families' (DCSF) recent report "Gender and Education: the evidence on pupils in England" showed that there has been a long-standing gender gap in GCSE attainment. Since 1988, girls have become significantly more likely than boys to achieve five or more GCSEs at grades $A^{*}-C$. This gap quickly increased and subsequently became stable at around a 10 percentage points, with little variation since 1995 . The gender gap is currently 9.2 percentage points: $65 \%$ of girls and $55.8 \%$ of boys achieved 5+ $A^{*}$-C GCSEs or equivalent in 2007. 
Figure 3: Percentage of 15 year olds pupils in England achieving 5+ $A *-C$ GCSEs (or equivalent), by gender, 1963-2007

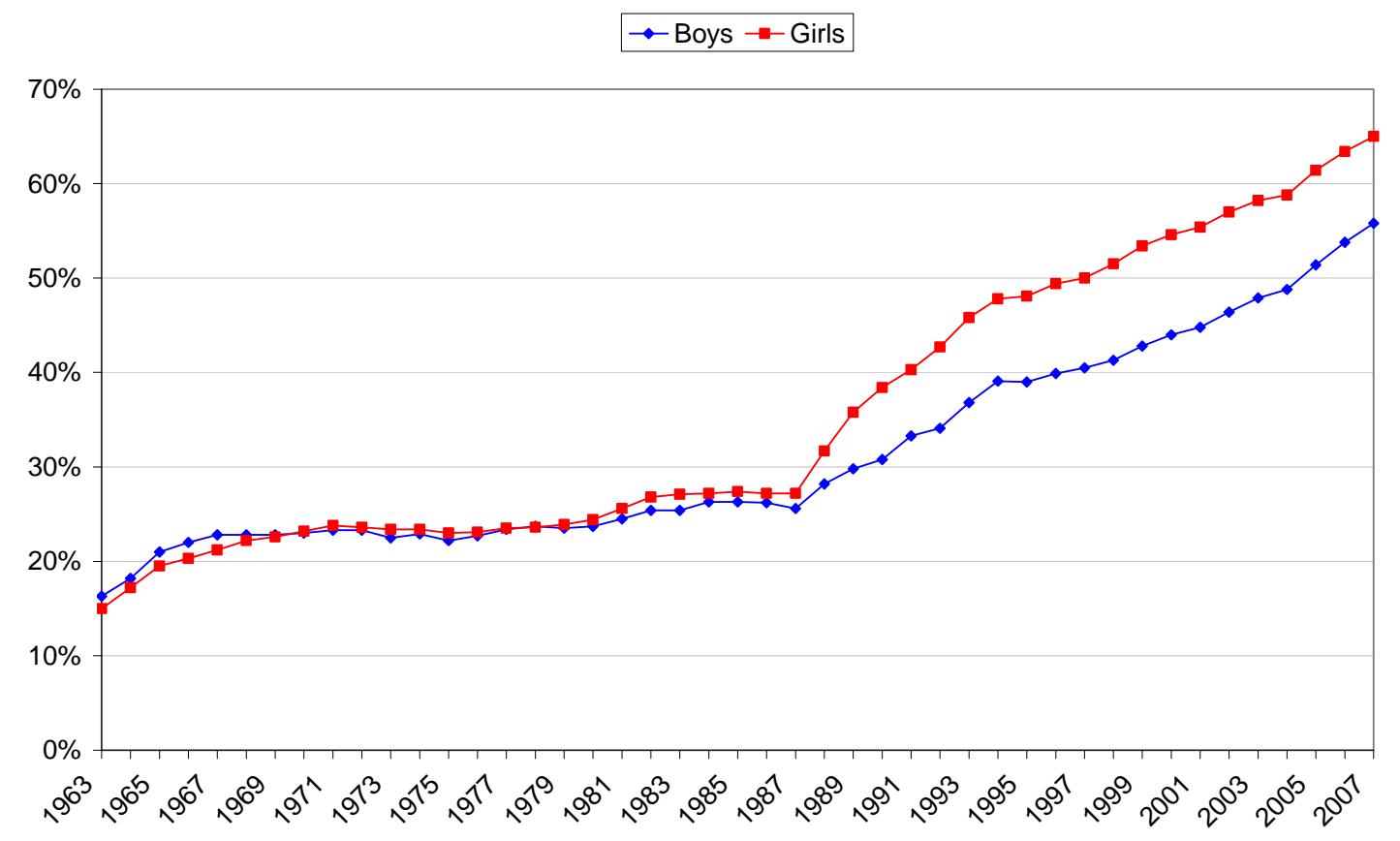

Note: Up until 1986, only O-level results were recorded in Statistics of Education, but between 1986 and 1988 O-levels and CSEs were both recorded. This caused a small increase in the numerator (as grade 1 CSE passes were added to O-level passes) and a much larger increase in the denominator, as all CSE entries were included. GCSEs replaced O-Levels in 1988, which is when the gap between men and women really opened up.

5. Post-16 participation rates also vary by gender. Girls are more likely to stay on in full time education at age 16 ( $82 \%$ of girls and $72 \%$ of boys). 
Figure 4: Participation in full-time education and training of 16 year old males and females, England, 1985 onwards

$\rightarrow-\rightarrow$ Females $\square \rightarrow-$ Males

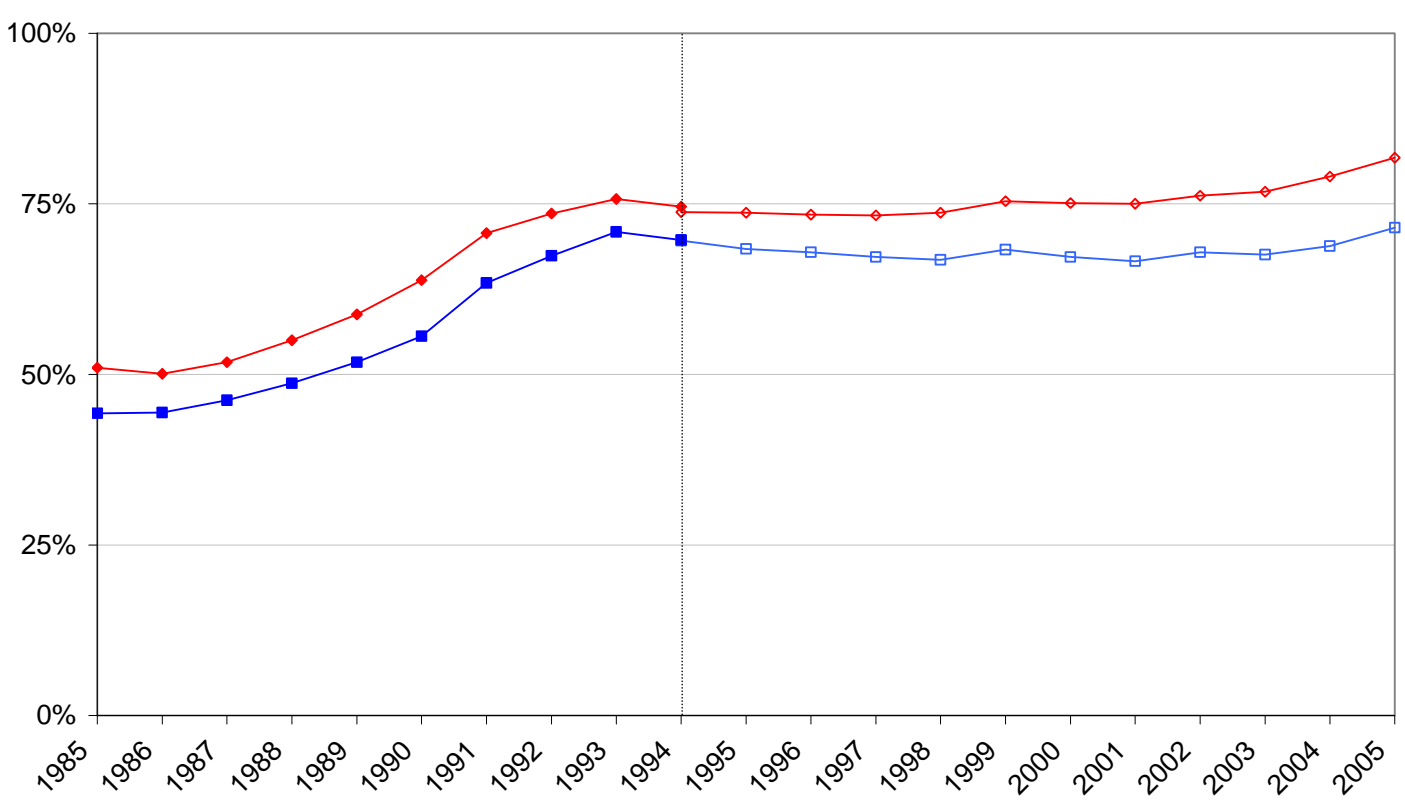

Note: The break in time series is due to changes in the source of further and higher education data.

Source: SFR 21/2006 http://www.dfes.gov.uk/rsgateway/DB/SFR/s000658/index.shtml

6. Girls are also more likely to be entered for A Levels than boys (54\% of entries are female), in contrast to the 1950s and 1960s when only a third of A-Level entries were female. Gender differences in pass rates for those entered for A-Levels are much narrower, but differences still exist. Across all subjects, the range of difference is 4 percentage points: 
Figure 5: Percentage of 16-18 year old candidates in England achieving two or more GCE/VCE A-Level passes, by gender (1994-2006)

- Males $₫$ Females

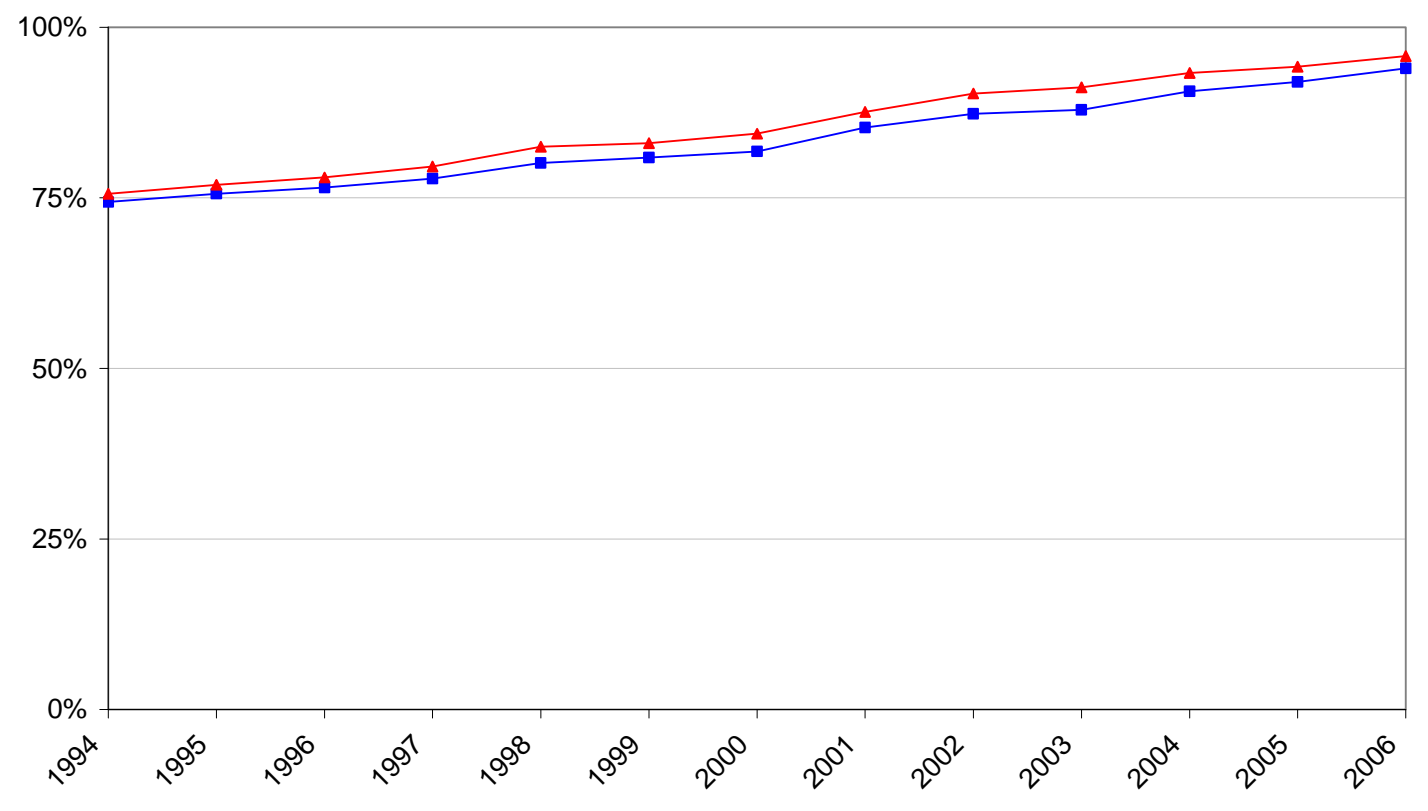

7. Finally, girls also perform better than boys in terms of those attaining an A grade (for the majority of subjects), which is a significant change over the last ten years.

Figure 6: Percentage of A level entrants in England achieving an $A$ grade at $A$ Level, by gender (1996-2006)

$$
\rightarrow \text { Males } \rightarrow \text { Females }
$$

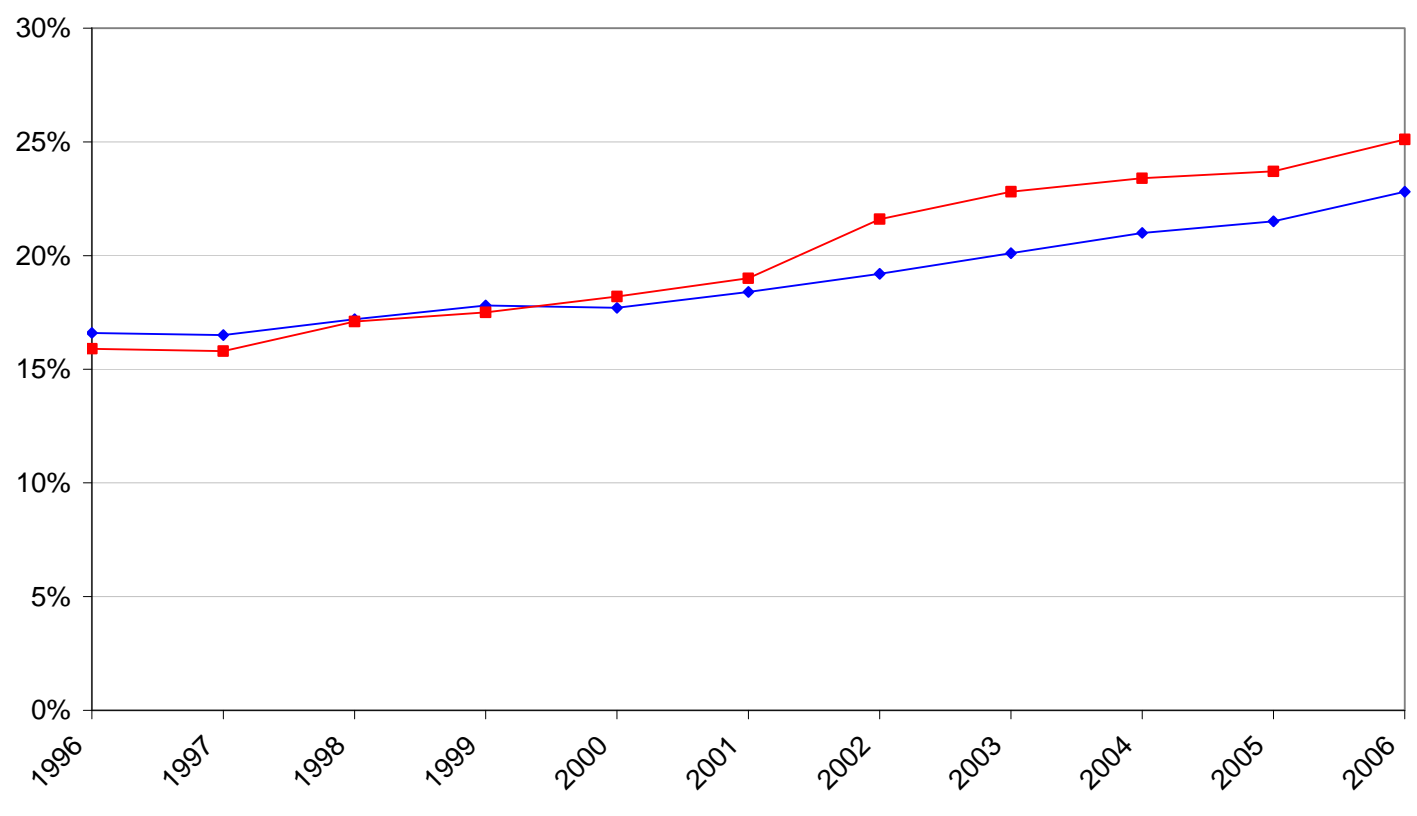

7 


\section{Structure and Purpose of this Paper}

8. The main purpose of this paper is to explore the extent to which the gender gap in HE participation is related to prior attainment, but we shall also extend this analysis for young people from different socio-economic and ethnic backgrounds. Although such gaps have previously been analysed using the Youth Cohort Survey ${ }^{8}$, small sample sizes and large and differential attrition rates by gender and prior attainment ${ }^{9}$ meant that we could never be certain about the extent to which the gender gap in HE participation closed after controlling for prior attainment.

9. Recently, English pupils' school records in the National Pupil Database (NPD) have been linked to student records kept by the Higher Education Statistics Agency (HESA). These administrative datasets allow us to analyse the relationship between $\mathrm{HE}$ participation and prior attainment in greater detail and certainty - although the lack of information on pupil characteristics for young people in independent schools means that the analysis is often (and will be in this paper) restricted to pupils in maintained schools only. In addition, the cut of the data we worked on did not include Individual Learner Record (ILR) data, and hence excludes all records of young people who may have been in HE in Further Education (FE) colleges. So, unless otherwise stated, all findings in this paper based on the linked administrative data apply to young people who are English-domiciled, did not attend an independent school in Year 11, and are not in HE in a FE college. ${ }^{10}$ In addition, we only look at participation in UK HEIs.

10. All findings based on the YCS will be on an equivalent basis - except for the fact that they will also include HE in FE. Although, technically speaking, it is possible, on the YCS, to filter out those who are on a HE course in a FE college, attrition and / or response rates to certain questions between Sweeps 3 and 4 of Cohort 12 affected the proportion of students studying in a university or a higher education college in such a way that it makes these variables unfit to be used in our analysis. Instead, we have had to base our analysis on the type of qualification sought which, unfortunately, does not allow us to distinguish between the types of institution studied at.

11. Despite these differences between the analyses carried out on the two datasets available to us, a secondary outcome of this paper will be a comparison of the "stories" the two datasets tell us about the relationship between gender and prior attainment. Although not a primary aim of this paper, this comparison is an important one, since the YCS, with its wealth of qualitative and contextual information, will

\footnotetext{
${ }^{8}$ See, for instance, the DCSF SFR series "The Activities and Experiences of [18/19] year olds: England and Wales".

${ }^{9}$ See section III for more detail on the Youth Cohort Survey, including its coverage and its weaknesses.

${ }^{10}$ The calculations underpinning the HEIPR 17-30 suggest that between nine and ten per cent of HE is provided in FE colleges.
} 
continue to be an invaluable source of information on the participation of young people in $\mathrm{HE}$, which linked administrative data will never be able to provide.

12. It is important to point out that this paper will look at young participation only (18 and 19 year olds) - and this narrow focus is dictated by the availability of data. ${ }^{11}$ In analysing gender participation gaps, this tells only part of the story, since we know that gender gaps persist for older age groups. ${ }^{12}$

13. This paper will not attempt to look at the causes of the attainment gaps that exist between men and women. A vast literature exists on this topic and, as a general introduction, the reader is referred to DCSF's recent topic paper on gender: "Gender and education: the evidence on pupils in England". Nor will we be concerned with differences in types of participation by men and women. For instance, well-known differences exist in subject choice between men and women ${ }^{13}$, as well as in mode of study $^{14}$.

14. Finally, it is important to point out that we are modelling participation in HE, rather than demand for HE. This is because the data available to us (YCS and HESA) only allow us to analyse outcomes, and not the intermediate stage of applications. For the latter, UCAS data on applicants would be necessary. A recent UCAS report found that, despite women being over-represented in $\mathrm{HE}$, they were more likely not to be placed at the end of the application cycle than men (UCAS 2007). ${ }^{15}$

15. The remainder of this paper is structured as follows. In the next section, we will describe the datasets we used for this study (YCS and NPD-HESA administrative dataset). In section IV we look at the relationship between gender gaps in $\mathrm{HE}$ participation and prior attainment gaps. We follow up on this discussion by looking at gender participation gaps over time, and by comparing these gaps with other gaps in HE participation. We do this in section V. Section VI summarises the findings and concludes.

\footnotetext{
${ }^{11}$ As time passes and subsequent years of HESA data are linked into earlier NPD/PLASC records, analyses of older participation will become possible.

${ }^{12}$ For instance, the latest DfES publication on "Participation rates in higher education: Academic years 1999/2000 - 2005/2006 (Provisional)" (http://www.dfes.gov.uk/rsgateway/DB/SFR/s000716/SFR10_2007v1.pdf) includes a HEIPR for 17-20 year olds, and one for 17-60 year olds. The latest HEIPR figure for 21-30 year old males was $7.1 \%$, and $10.4 \%$ for $21-30$ year olds females (i.e. a 3.3 percentage point gap); and the equivalent figures for $31-60$ year old males and females were $6.9 \%$ and $12.6 \%$, respectively (i.e. a 5.4 percentage point gap).

${ }^{13}$ Women outnumber men in nearly all subject groups, apart from Business and Administrative Studies; Physical Sciences; Mathematical Sciences; Architecture, Building and Planning; Computer Science; and Engineering and Technology. Subjects which are primarily taken by women include: Subjects Allied to Medicine, Education and Languages. Women are also over-represented in Veterinary Sciences, Medicine, Dentistry, and Law.

${ }^{14}$ Women are more likely to study part-time than men. According to HESA data for 2005/06, $42.2 \%$ of English-domiciled women who enrolled in undergraduate HE did so on part-time courses, compared with $35.3 \%$ of English-domiciled men. However, it should be pointed out that women considerably outnumber men even in full-time study: $56.0 \%$ of English-domiciled undergraduate students in 2005/06 were female. The Full-Time HEIPR for women is $41.0 \%$, compared to $32.5 \%$ for men.

${ }^{15}$ Primary UCAS statistics tell the same story - http://search1.ucas.co.uk/fandf00/index.html For instance, for entry in 2006, 82.6\% of English-domiciled men who applied to English institutions were accepted, compared to $79.3 \%$ of English-domiciled women who applied to English institutions. This is true for pretty much all age groups, apart from the 40+ group.
} 


\section{Data}

16. We used two datasets for the analysis in this paper: the Youth Cohort Study (YCS) and the linked NPD-HESA dataset. In this section, we shall discuss each in turn, including basic descriptive statistics on HE participation by gender. The main conclusions (for those readers wishing to skip this more technical section) are that attrition rates on the YCS are worse for males than for females, and that they are worse for low-attaining individuals than for high-attaining ones. Together (and despite the use of weights to correct for this attrition), this means that the YCS exaggerates the gender gap in HE participation (and other measures of educational attainment) although it does correctly show that females have an advantage on all measures.

\section{The Youth Cohort Study}

17. The Youth Cohort Studies are a series of longitudinal surveys of young people aged 16 and upwards, which monitor their decisions and behaviour in making the transition from compulsory education to Further or Higher education, employment or another activity. YCS cohorts are selected by taking a sample designed to be representative of all Year 11 pupils in England and Wales (excluding those in special schools). The first survey (or 'sweep') of those sampled takes place one year later, with subsequent sweeps at varying time intervals (usually annually but occasionally after shorter intervals).

18. For the purposes of this paper, we used YCS Cohort 12 (young people of academic age 16 in 2003/04, and of academic age 19 in 2006/07). In Sweep 1 of Cohort 12, there were 12,005 English-domiciled respondents of academic age 16 who were in maintained schools in Year 11. By Sweep 4, there were only 3,787 such young people (i.e. $31.5 \%$ of the original number). As Table 1 below indicates, the attrition rate for males is worse than that for females: $44.1 \%$ of respondents were male in Sweep $1^{16}$; by Sweep 4, only $39.0 \%$ were male. ${ }^{17}$ Although the use of weights ${ }^{18}$ in the YCS attempts to correct for this imbalance, the adjustment will never be perfect (Table 2) and, even if the weights managed to get us back to the population equivalent gender split, there may still be differential response biases between males and females that weights cannot control for.

\footnotetext{
${ }^{16}$ The issued sample for YCS Cohort 12 was 30,000 (including both Welsh- and Englishdomiciled students) and a success rate of $46.7 \%$ was achieved. The sampling frame indicated a target of 51\% males to correspond with Year 11 school registers for 2002/03, but Sweep 1 contained only $44.1 \%$ male respondents.

${ }^{17}$ Note that the higher male mortality in these age ranges means that we would not expect the same sex proportions across sweeps, even if we had no attrition.

${ }^{18}$ The YCS data was weighted to correct for biases which arose due to differences in selection probabilities, and differential response rates. Three types of weight were created: selection weights; ethnic boost weights, and non-response weights. The final weight was calculated as the product of all three weights.
} 
Table 1: Number of English-domiciled respondents who were in maintained schools in Year 11, in each sweep of YCS Cohort 12, by gender (unweighted)

\begin{tabular}{|l|c|c|c|c|c|c|c|c|}
\hline & \multicolumn{2}{|c|}{ Sweep 1 } & \multicolumn{2}{c|}{ Sweep 2 } & \multicolumn{2}{c|}{ Sweep 3 } & \multicolumn{2}{c|}{ Sweep 4 } \\
\hline & Number & Percent* $^{\star}$ & Number & Percent* & Number & Percent* & Number & Percent* $^{\star}$ \\
\hline Male & 5,294 & 44.1 & 3,519 & 42.1 & 2,442 & 41.6 & 1,477 & 39.0 \\
\hline Female & 6,711 & 55.9 & 4,846 & 57.9 & 3,433 & 58.4 & 2,310 & 61.0 \\
\hline Total & 12,005 & 100 & 8,365 & 100 & 5,875 & 100 & 3,787 & 100 \\
\hline
\end{tabular}

* Percentage of Sweep that is Male / Female.

Table 2: Number of English-domiciled respondents who were in maintained schools in Year 11, in each sweep of YCS Cohort 12, by gender (weighted)

\begin{tabular}{|l|c|c|c|c|c|c|c|c|}
\hline & \multicolumn{2}{|c|}{ Sweep 1 } & \multicolumn{2}{c|}{ Sweep 2 } & \multicolumn{2}{c|}{ Sweep 3 } & \multicolumn{2}{c|}{ Sweep 4 } \\
\hline & Number & Percent* $^{\star}$ & Number & Percent* $^{\star}$ & Number & Percent* $^{\star}$ & Number $^{\text {Percent* }^{*}}$ \\
\hline Male & 6,228 & 50.7 & 4,268 & 49.6 & 3,028 & 50.0 & 1,957 & 50.0 \\
\hline Female & 6,052 & 49.3 & 4,344 & 50.4 & 3,027 & 50.0 & 1,953 & 50.0 \\
\hline Total & 12,280 & 100 & 8,612 & 100 & 6,055 & 100 & 3,910 & 100 \\
\hline
\end{tabular}

* Percentage of Sweep that is Male/Female.

19. Attrition rates do not only vary by gender, but also by prior attainment: in Sweep 1, 33.6\% of English-domiciled respondents in maintained schools had attained fewer than 5 'good' GCSEs (i.e. A*-C). By Sweep 4, that percentage had fallen to $23.4 \%{ }^{19}$ Again, weights attempt to correct for these different attrition rates (Tables 3 and 4). Interestingly, the attrition rate for females attaining 5 or more good GCSEs is quite a bit lower than that for males attaining 5 or more good GCSEs (Tables 5 and 6). 40\% of females with five good GCSEs present in Sweep 1 re-appear in Sweep 4, compared to $31 \%$ of males with five good GCSEs in Sweep 1 . This will partly explain why the YCS exaggerates the gender gap in HE participation (very few pupils who did not achieve 5 good GCSEs will go on to HE) - and we shall return to this point when we look at the relationship between gender gaps in HE participation and prior attainment in section IV below.

Table 3: Number of English-domiciled respondents who were in maintained schools in Year 11, in each sweep of YCS Cohort 12 achieving 5+ A*-C GCSES (unweighted)

\begin{tabular}{|l|l|c|c|c|c|c|c|c|}
\hline & \multicolumn{2}{|c|}{ Sweep 1 } & \multicolumn{2}{c|}{ Sweep 2 } & \multicolumn{2}{c|}{ Sweep 3 } & \multicolumn{2}{c|}{ Sweep 4 } \\
\hline & Number & Percent* $^{*}$ & Number & Percent* $^{*}$ & Number & Percent $^{\star}$ & Number & Percent* $^{\star}$ \\
\hline$<5$ & 4,034 & 33.6 & 2,373 & 28.4 & 1,503 & 25.6 & 886 & 23.4 \\
\hline $5+$ & 7,971 & 66.4 & 5,992 & 71.6 & 4,372 & 74.4 & 2,901 & 76.6 \\
\hline Total & 12,005 & 100 & 8,365 & 100 & 5,875 & 100 & 3,787 & 100 \\
\hline
\end{tabular}

* Percentage of Sweep (not) attaining five good GCSEs.

\footnotetext{
${ }^{19}$ Please not that this relates to GCSE attainment at a fixed point in time (Sweep 1) and does not take account of subsequent GCSE awards.
} 
Table 4: Number of English-domiciled respondents who were in maintained schools in Year 11, in each sweep of YCS Cohort 12 achieving 5+ $A^{*}$-C GCSES (weighted)

\begin{tabular}{|l|c|c|c|c|c|c|c|c|}
\hline & \multicolumn{2}{|c|}{ Sweep 1 } & \multicolumn{2}{c|}{ Sweep 2 } & \multicolumn{2}{c|}{ Sweep 3 } & \multicolumn{2}{c|}{ Sweep 4 } \\
\hline & Number & Percent $^{\star}$ & Number & Percent* $^{\star}$ & Number & Percent* $^{*}$ & Number & Percent* $^{\star}$ \\
\hline$<5$ & 5,890 & 48.0 & 4,128 & 47.9 & 2,798 & 46.2 & 1,801 & 46.1 \\
\hline $5+$ & 6,390 & 52.0 & 4,484 & 52.1 & 3,257 & 53.8 & 2,109 & 53.9 \\
\hline Total & 12,280 & 100 & 8,612 & 100 & 6,055 & 100 & 3,910 & 100 \\
\hline
\end{tabular}

* Percentage of Sweep (not) attaining five good GCSEs.

Table 5: Number of English-domiciled respondents who were in maintained schools in Year 11, in each sweep of YCS Cohort 12 achieving 5+ A*-C GCSEs, by gender (unweighted)

\begin{tabular}{|l|c|c|c|c|c|c|c|c|}
\hline & \multicolumn{2}{|c|}{ Sweep 1 } & \multicolumn{2}{c|}{ Sweep 2 } & \multicolumn{2}{c|}{ Sweep 3 } & \multicolumn{2}{c|}{ Sweep 4 } \\
\hline & Number & Percent* $^{*}$ & Number & Percent $^{\star}$ & Number & Percent* & Number & Percent* $^{\star}$ \\
\hline Male & 3,324 & 62.8 & 2,394 & 68.0 & 1,700 & 69.6 & 1,038 & 70.3 \\
\hline Female & 4,647 & 69.2 & 3,598 & 74.2 & 2,672 & 77.8 & 1,863 & 80.6 \\
\hline Total & 7,971 & 66.4 & 5,992 & 71.6 & 4,372 & 74.4 & 2,901 & 76.6 \\
\hline
\end{tabular}

* Percentage of gender attaining five good GCSEs in each Sweep.

Table 6: Number of English-domiciled respondents in each sweep of YCS Cohort 12 achieving 5+ * $^{*}$-C GCSEs, by gender (weighted)

\begin{tabular}{|l|c|c|c|c|c|c|c|c|}
\hline & \multicolumn{2}{|c|}{ Sweep 1 } & \multicolumn{2}{c|}{ Sweep 2 } & \multicolumn{2}{c|}{ Sweep 3 } & \multicolumn{2}{c|}{ Sweep 4 } \\
\hline & Number & Percent* $^{*}$ & Number & Percent $^{\star}$ & Number & Percent* & Number & Percent* $^{\star}$ \\
\hline Male & 2,945 & 47.3 & 2,040 & 47.8 & 1,472 & 48.6 & 937 & 47.9 \\
\hline Female & 3,445 & 56.9 & 2,444 & 56.3 & 1,785 & 59.0 & 1,172 & 60.0 \\
\hline Total & 6,390 & 52.0 & 4,484 & 52.1 & 3,257 & 53.8 & 2,109 & 53.9 \\
\hline
\end{tabular}

* Percentage of gender attaining five good GCSEs in each Sweep.

20. Finally, since in this paper we will also be looking at participation in HE by socioeconomic class and ethnicity, we present, in tables 7 and 8 below, the attrition rates by these two characteristics as well. The attrition rates for young people from lower socio-economic classes are higher than those for young people from higher socioeconomic classes. The attrition rates of young people from non-white minority ethnic ${ }^{20}$ backgrounds are only marginally lower than those for young people from White backgrounds. It is also worth pointing out (not shown in the tables below) that the attrition rate of low-achieving young people from lower socio-economic classes is higher than that of low-achieving people from higher socio-economic classes. The

\footnotetext{
${ }^{20}$ In this paper, any reference to minority ethnic groups will refer to all non-White ethnic groups. Such overall grouping of ethnicities in educational research is rarely justified, as there are important differences between these groups in terms of educational attainment. For this reason, we shall also consider HE participation rates for each of the more detailed ethnic groupings later on in this section.
} 
attrition rate of low-achieving people from non-White backgrounds is only marginally lower than that of low-achieving people from White backgrounds.

Table 7: Number of English-domiciled respondents who were in maintained schools in Year 11, by Socio-Economic Class (unweighted)

\begin{tabular}{|l|c|c|c|c|c|c|c|c|}
\hline & \multicolumn{2}{|c|}{ Sweep 1 } & \multicolumn{2}{c|}{ Sweep 2 } & \multicolumn{2}{c|}{ Sweep 3 } & \multicolumn{2}{c|}{ Sweep 4 } \\
\hline & Number & Percent $^{\star}$ & Number & Percent* & Number & Percent & Number & Percent* \\
\hline $\begin{array}{l}\text { Higher and Lower } \\
\text { Professional }\end{array}$ & 5,454 & 45.4 & 4,095 & 49.0 & 2,959 & 50.4 & 1,948 & 51.4 \\
\hline $\begin{array}{l}\text { Intermediate, Lower } \\
\text { Supervisory and Routine }\end{array}$ & 5,186 & 43.2 & 3,460 & 41.4 & 2,389 & 40.7 & 1,525 & 40.3 \\
\hline Unknown & 1,365 & 11.4 & 810 & 9.7 & 527 & 9.0 & 314 & 8.3 \\
\hline Total & 12,005 & 100 & 8,365 & 100 & 5,875 & 100 & 3,787 & 100 \\
\hline
\end{tabular}

* Percentage of Sweep from each Socio-Economic Class.

Table 8: Number of English-domiciled respondents who were in maintained schools in Year 11, by Ethnicity (unweighted)

\begin{tabular}{|l|c|c|c|c|c|c|c|c|}
\hline & \multicolumn{2}{|c|}{ Sweep 1 } & \multicolumn{2}{c|}{ Sweep 2 } & \multicolumn{2}{c|}{ Sweep 3 } & \multicolumn{2}{c|}{ Sweep 4 } \\
\hline & Number & Percent* & Number & Percent* & Number & Percent* & Number & Percent* \\
\hline White & 9,950 & 82.9 & 6,956 & 83.2 & 4,876 & 83.0 & 3,135 & 82.8 \\
\hline Non-white & 1,829 & 15.2 & 1,272 & 15.2 & 906 & 15.4 & 597 & 15.8 \\
\hline Unknown & 226 & 1.9 & 137 & 1.6 & 93 & 1.6 & 55 & 1.5 \\
\hline Total & 12,005 & 100 & 8,365 & 100 & 5,875 & 100 & 3,787 & 100 \\
\hline
\end{tabular}

* Percentage of Sweep from each Ethnicity.

\section{Linked NPD-HESA Administrative Data}

21. National Pupil Database (NPD) and Pupil Level Annual Schools Census (PLASC) records have recently been linked to the Higher Education Statistics Agency (HESA) student records for 2004/05 and for 2005/06. Our analysis is based on an extract of this dataset which includes 610,107 students for whom we have Key Stage 4 or school census information for 2001/02. 48,667 of these students were not in maintained schools in 2001/02, and so were excluded from our analysis (mainly because PLASC records, and hence pupil-level characteristics, are missing for most of these pupils). 
22. $49.0 \%$ of our sample are female ( 2 cases have missing gender information ${ }^{21}$ ); $14.4 \%$ were on Free School Meals (FSM) in their last year of compulsory schooling (FSM status is unknown for $0.56 \%$ of our sample, or 3,142 cases). And the ethnicity makeup of our sample is:

Table 9: Ethnicity of NPD-HESA sample used in the analysis

\begin{tabular}{|l|c|c|}
\hline Ethnicity & Frequency & Percent \\
\hline White, UK & 463,639 & 82.58 \\
\hline White, European & 10,921 & 1.95 \\
\hline White, Other (known) & 3,328 & 0.59 \\
\hline White, Type not known & 872 & 0.16 \\
\hline Black, Caribbean & 7,805 & 1.39 \\
\hline Black, African & 6,863 & 1.22 \\
\hline Black, Other & 4,417 & 0.79 \\
\hline Indian & 13,902 & 2.48 \\
\hline Pakistani & 14,060 & 2.5 \\
\hline Bangladeshi & 5,145 & 0.92 \\
\hline Chinese & 2,006 & 0.36 \\
\hline Mixed & 806 & 0.14 \\
\hline Unknown & 27,671 & 4.93 \\
\hline Missing & 5 & 0 \\
\hline
\end{tabular}

23. 108,911 young people in our dataset were in $\mathrm{HE}^{22}$ at age 18 in 2004/05, and 151,961 in $\mathrm{HE}$ at age 19 in 2005/06. This compares to 134,775 English-domiciled 18 year old enrolments in the HESA Standard Registration Population for 2004/05, and 194,875 19 year old enrolments in the 2005/06 HESA Standard Registered Population. It is not entirely clear why these discrepancies exist - although preliminary analysis of the "previous institution" field on the HESA field suggests that a large number of students have either no information on their previous institution, or attended a non-state or foreign school, so would not be expected to appear in our matched dataset.

24. Finally, 20,384 individuals (3.63\%) in our sample have no information at all on their GCSE performance. This could be for various reasons: they could have dropped out of school before the end of compulsory education; they could not have sat their exams yet; or they could have sat any of the vocational qualifications, other than GNVQs, information on which was not collected prior to 2004. For the purposes of this paper, we have tended to include dummy variables to control for individuals who

\footnotetext{
${ }^{21}$ In all subsequent regressions, cases with missing variable information will be dropped.

${ }^{22}$ We only count students who were in the HESA Standard Registration Population as being in $\mathrm{HE}$.
} 
have no GCSE attainment information. Although is very likely that the GCSE attainment of these individuals was, in fact, zero ${ }^{23}$ - it seemed safer to deal with them using a dummy variable since GCSE attainment information appeared not to be missing at random: it was missing for $4.2 \%$ of men, compared to $3.0 \%$ of women; it was much more likely to be missing for Black students (5.7\%) than for White students (3.5\%) or Asian students (2.8\%); pupils on FSM appeared to be particularly affected (7.1\% compared to $2.8 \%$ for non-FSM pupils); and students who were in HE by 19 were much less likely to have missing GCSE score information $(0.4 \%)$ than young people who were not in HE by 19 (4.9\%).

\section{Comparisons between the YCS and the Linked Administrative Data}

25. Table 10 below summarises what Cohort 12 of the YCS tells us about gender gaps in some key measures of educational attainment and participation. These gaps are all consistently in favour of women, and are all statistically significant.

Table 10: Gender gaps in some key measures of attainment and participation, YCS Cohort 12 (weighted) - English-domiciled young people not in independent schools in Year 11

\begin{tabular}{|l|c|c|}
\cline { 2 - 3 } \multicolumn{1}{c|}{} & Men & Women \\
\hline Proportion attaining 5+ GCSEs A*-C (or equivalents) at end of year 11 & $46 \%$ & $54 \%$ \\
\hline Average GCSE point attainment at end of year 11 ${ }^{24}$ & 40 & 45 \\
\hline Proportion attaining 2+ A/As and AVCE by age 18 & $32 \%$ & $41 \%$ \\
\hline Proportion attaining 2+ A/As by age 18 & $30 \%$ & $37 \%$ \\
\hline Proportion doing a first degree by 18 & $22 \%$ & $27 \%$ \\
\hline Proportion doing a first degree by 19 & $31 \%$ & $39 \%$ \\
\hline Proportion in HE by 18 & $26 \%$ & $34 \%$ \\
\hline Proportion in HE by 19 & $36 \%$ & $47 \%$ \\
\hline
\end{tabular}

26. Table 11 below replicates some of these key measures of educational attainment and participation using the linked NPD-HESA data. The administrative data confirms the YCS finding that females have an advantage on all measures, although it is clear that the YCS overestimates attainment and participation for both genders, and at all stages. Considering the differential attrition rates by prior attainment documented in the previous section, this is not surprising.

\footnotetext{
${ }^{23}$ According to the following SFR publication http://www.dcsf.gov.uk/rsgateway/DB/SFR/s000702/SFR01-2007.pdf the proportion of 15 year olds that are estimated not to achieve any passes at GCSE or equivalent at all stands at $2.2 \%$.

${ }^{24}$ Here, as everywhere else in this paper, GCSE point score refers to the old system of calculating the total sum of an individual's GCSEs, where $A^{*}=8, A=7, B=6, C=5, D=4, E=3$, $F=2, G=1$. Here, we take the total uncapped GCSE point score (i.e. the total of all the GCSE results for the individual, regardless of how many GCSEs s/he sat). Elsewhere in this paper, we also used the capped GCSE point score - the total of that individual's best 8 GCSE results - and average GCSE scores.
} 
Table 11: Gender gaps in some key measures of attainment and participation, NPD-HESA - English-domiciled young people in maintained schools in Year 11

\begin{tabular}{|l|c|c|}
\cline { 2 - 3 } \multicolumn{1}{c|}{} & Men & Women \\
\hline Proportion attaining 5+ GCSE A*-C at Key Stage 4 & $44 \%$ & $55 \%$ \\
\hline Average GCSE point attainment at Key Stage 4 & 38 & 43 \\
\hline $\begin{array}{l}\text { Proportion attaining 2+ GCE/VCE A/As Level and GCE } \\
\text { As/VCE Double Award Level passes at Key Stage 5 }\end{array}$ & $27 \%$ & $36 \%$ \\
\hline $\begin{array}{l}\text { Proportion attaining 2+ GCE A/As Level passes at Key } \\
\text { Stage 5 }\end{array}$ & $24 \%$ & $31 \%$ \\
\hline Proportion in HE by 18 (excluding HE in FE) & $17 \%$ & $22 \%$ \\
\hline Proportion in HE by 19 (excluding HE in FE) & $25 \%$ & $32 \%$ \\
\hline
\end{tabular}

\section{Gender Gaps and Prior Attainment}

27. In this section, we will investigate what the data tell us about the relationship between gender gaps in HE participation and prior attainment. We find that very simple controls for prior attainment greatly reduce the effect of gender on HE participation, although they do not eliminate it entirely. Our econometric models do not allow us to draw any clear conclusions about the significance or the direction of the gender effect, once prior attainment is controlled for. However, even if a gender effect persists after controlling for prior attainment, we find that this is very small, particularly in comparison to the effect of increasing prior attainment.

28. As we saw in the previous section, the YCS suggests that, in $2006 / 07$, there was a 11 percentage point gap in HE participation by age 19 between English-domiciled men and women who attended maintained schools in Year 11. Similarly, the linked administrative data tells us that there was a 7 percentage point gender gap in HE participation in 2005/06. However, we also know that women have higher prior attainment than men, so we would like to know to what extent this gap narrows once we compare men and women with similar levels of prior attainment.

29. In the following diagram, we have split up our YCS sample into quintiles according to GCSE point score attainment (uncapped). For each quintile, we then compare the participation rate of men with that of women and we find that the participation gaps are reduced (from an overall 11 percentage point gap), but remain relatively large (up to 6 percentage points, depending upon the quintile).

${ }^{25}$ Average of those who achieved at least one pass. 
Figure 7: YCS Cohort 12: Proportion in HE by 19, by Gender and Quintile of GCSE Attainment (English-domiciled young people not in independent schools in Year 11)

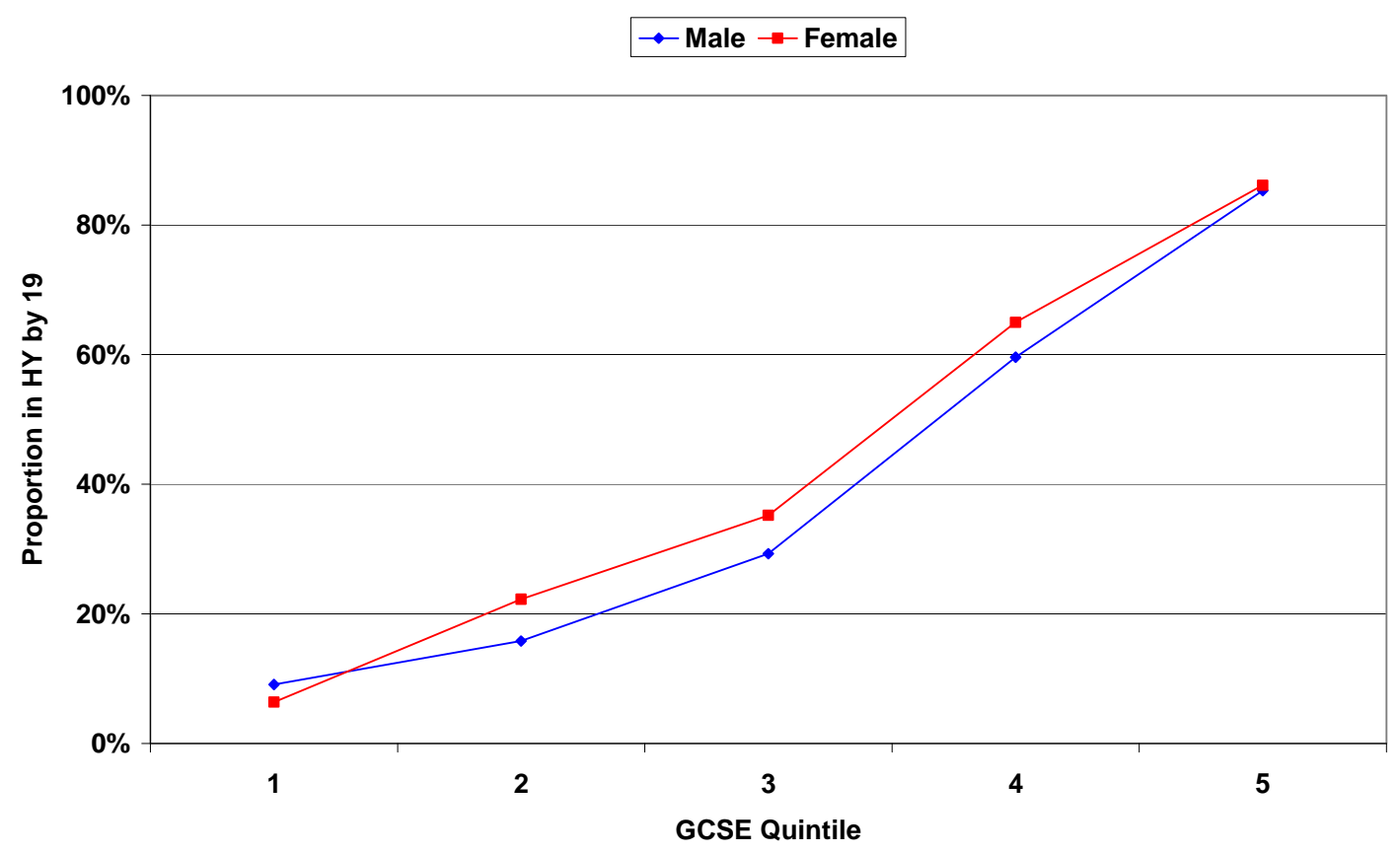

30. The NPD-HESA data allows much more detailed analysis of the relationship between prior attainment and HE participation (over 550,000 observations, compared to under 4,000 on our YCS sample). Figure 8 replicates Figure 7 above, except that we have now split up pupils into "fifteenth" of GCSE attainment rather than quintiles (where GCSE attainment is measured by the total uncapped point score). From an overall gender participation gap of 7.3 percentage points, the largest gaps seen in the diagram below range from -1.3 percentage points in favour of men, to 0.6 percentage points in favour of women. 
Figure 8: NPD-HESA: Proportion in HE by 19, by Gender and Quintile of GCSE Attainment

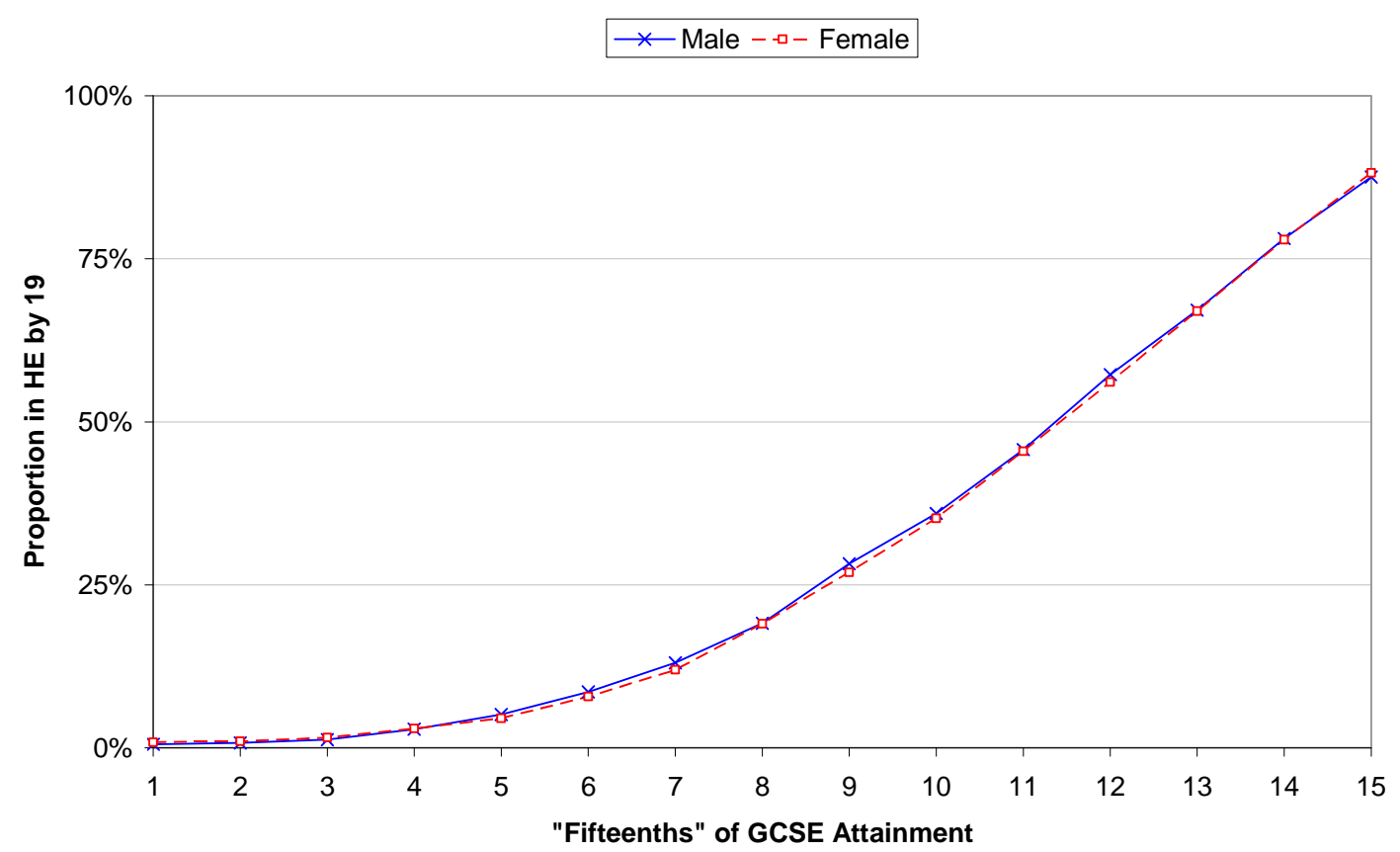

Note: does not include individuals with no GCSE attainment information.

31. A slightly more sophisticated way of controlling for prior attainment would be to use a regression model with a binary outcome. One such model is the probit regression model, which provides estimates of the strength of the relationship between the explanatory variables and the outcome variable of interest.

32. We ran several probit regressions on the dichotomous outcome variables "In HE by 18" and "In HE by 19". Modelling entry at both these ages separately allows us to account to a certain extent for both the likelihood of gap years and the possibility of dropping out between 18 and 19 differing between males and females.

33. As explanatory variables, we used a dummy variable for gender (taking the value of 1 when the individual is female, and 0 otherwise) and we used achievement at GCSE (or equivalent) as our base control for prior attainment, as such information was available for almost the entire cohort on a comparable basis (unlike A Level or other Level 3 qualifications, where selection issues start playing a role). We experimented with three different GCSE variables: (i) the total uncapped point score of the individual (calculated using the old system - see footnote 24); (ii) the total capped point score of the individual (i.e. taking the sum of the individual's best 8 GCSEs) ${ }^{26}$; and (iii) the individual's average GCSE attainment. In addition, we included quadratic and cubic terms of these GCSE attainment variables in some of our regressions, to allow for non-linear relationships between the individual's attainment and their likelihood of participating in HE.

${ }^{26}$ The total capped point score was not used in the YCS regressions. 
34. First, we discuss the regression results using Cohort 12 of the YCS. The full output from the regression analysis can be found in Annex 1 . In none of the regressions using the individuals' average GCSE point score did we find a significant gender effect. The only significant gender effect was found when we used the total (uncapped) point score to control for prior attainment - in which case four out of six regressions suggested a marginally significant (5\% level) effect, with women slightly more likely than men to be in $\mathrm{HE}$, even after controlling for prior attainment. Overall, however, gender was not found to be significant in 8 of the 12 models we ran on the YCS.

35. Turning to the results of the regressions on the linked administrative data, presented in full in Annex 2, we find that, in 8 of the 18 models we ran, the effect of gender is found to be insignificant after controlling for prior attainment - which is a particularly strong result, considering the large size of our dataset. By 18, we find some positive effects in favour of women, but by 19 this seems to reverse in favour of men (i.e. men are actually more likely to participate in $\mathrm{HE}$, after controlling for prior attainment). By 18 , the only significant gender effects we find are when we use total uncapped and average GCSE point score, whereas by 19, the significant gender effects appear when we use total capped and average GCSE point score.

36. Overall, these results (both on the YCS and on the linked administrative data) appear to support the conclusion that no clear gender effect can be found once we control for prior attainment using GCSE point scores. Moreover, even when a significant effect can be found, the size of it is negligible. For instance, taking Model 22, the difference in the predicted likelihood of participation in HE by age 19 between a man and a woman with average GCSE attainment is 0.4 percentage points. In comparison, increasing the GCSE attainment of an individual with average GCSE attainment by just one point (i.e. one grade increase in one GCSE) would increase the chances of that individual participating in HE by age 19 by 2.3 percentage points. 


\section{Gender Gaps in Perspective}

37. Although men are currently less likely to be in HE by age 19 than women, we have just seen that our data suggests that this gap turns very small (if not insignificant, or the other way round) once we control for prior attainment.

38. In this section, we shall see that the YCS suggests that this is a relatively new phenomenon and that, for previous cohorts of young people, women were clearly less likely to participate in HE than men, even after controlling for prior attainment. In addition, we'll compare the gender participation gap to the gaps that exist between young people from deprived backgrounds (whether measured by FSM or SocioEconomic Class) and those from privileged backgrounds; and the gaps that exist between young people from non-White minority ethnic groups and their White peers. We'll see that, in comparison to the gender gap, these gaps are: (i) larger and (ii) do not disappear entirely once prior attainment is taken into account (although most of the FSM/socio-economic class gap can be explained by prior attainment).

\section{Gender Gaps over Time}

39. Unfortunately, the linked NPD-HESA dataset cannot yet be used for comparisons of gender gaps over time. However, for the purpose of this paper, we analysed 8 successive cohorts of the YCS (starting with Cohort 5 through to Cohort 12 - i.e. starting with pupils eligible to leave school in 1989-90 and ending with those eligible to leave school in 2002/03).

40. Using the YCS for constructing time series is always discouraged because of the small sample sizes involved and the problems with attrition rates. In our analysis, we faced some additional problems which included: (i) poor documentation of the YCS variables (particularly for earlier cohorts); and (ii) changes in the way questions were asked over time, as well as in the timing of the questionnaires. For increased consistency, this section looks at 18 year olds and $1^{\text {st }}$ Degrees only ${ }^{27}$. Young people from Wales are excluded from the analysis; however we did not exclude students who had attended independent schools in Year 11. Finally, prior attainment is controlled for by the total uncapped GCSE point score of young people, but excluding equivalent qualifications.

\footnotetext{
${ }^{27}$ Cohorts 5 to 9 have a "qualifications" section, under which respondents are asked to tick any qualifications they are currently studying for: NVQ, GNVQ, BTEC, City and Guilds, RSA, GCSE, A Level, Degree - and at what level (e.g. BTEC First, National or Higher Diploma). Only if respondents ticked the "Degree" box did we consider them to be studying for a degree. From Cohort 10 onwards, the question in the "qualifications" section changed slightly. Respondents were still asked to tick the qualifications they were studying for, but all degreelevel courses (e.g. BTEC Higher Diploma) were subsumed under the question "Are you currently studying for a Higher Education qualification, such as a degree, Diploma in Higher Education, Initial Teacher Training, HND or similar?" When respondents answered "yes" to this question, they were subsequently asked what qualifications they were studying for: "Degree", "Diploma in Higher Education", "Initial Teacher Training", "HND" or "Other". We considered anyone who ticked "Degree", "Diploma in Higher Education" and "Initial Teacher Training" to be studying for a degree because: (i) these qualifications were not separately asked for in previous surveys (so they may have previously have been subsumed under "degree" anyway); and (ii) this seemed to provide the most consistent time series.
} 
41. Despite these caveats, the results of our analysis were very interesting and corroborate some of the hypotheses about the evolution in gender gaps in $\mathrm{HE}$ participation. On the one hand, the YCS confirms that the gender gap in participation has been widening over time. From a negative gap, women overtook men in 1992/93 (similar story as told by the API), and continued to increase their participation at a faster rate than men ever since.

Figure 9: The gender gap in HE participation over time $\left(1^{\text {st }}\right.$ Degree by age 18),YCS Cohorts 5 to 12

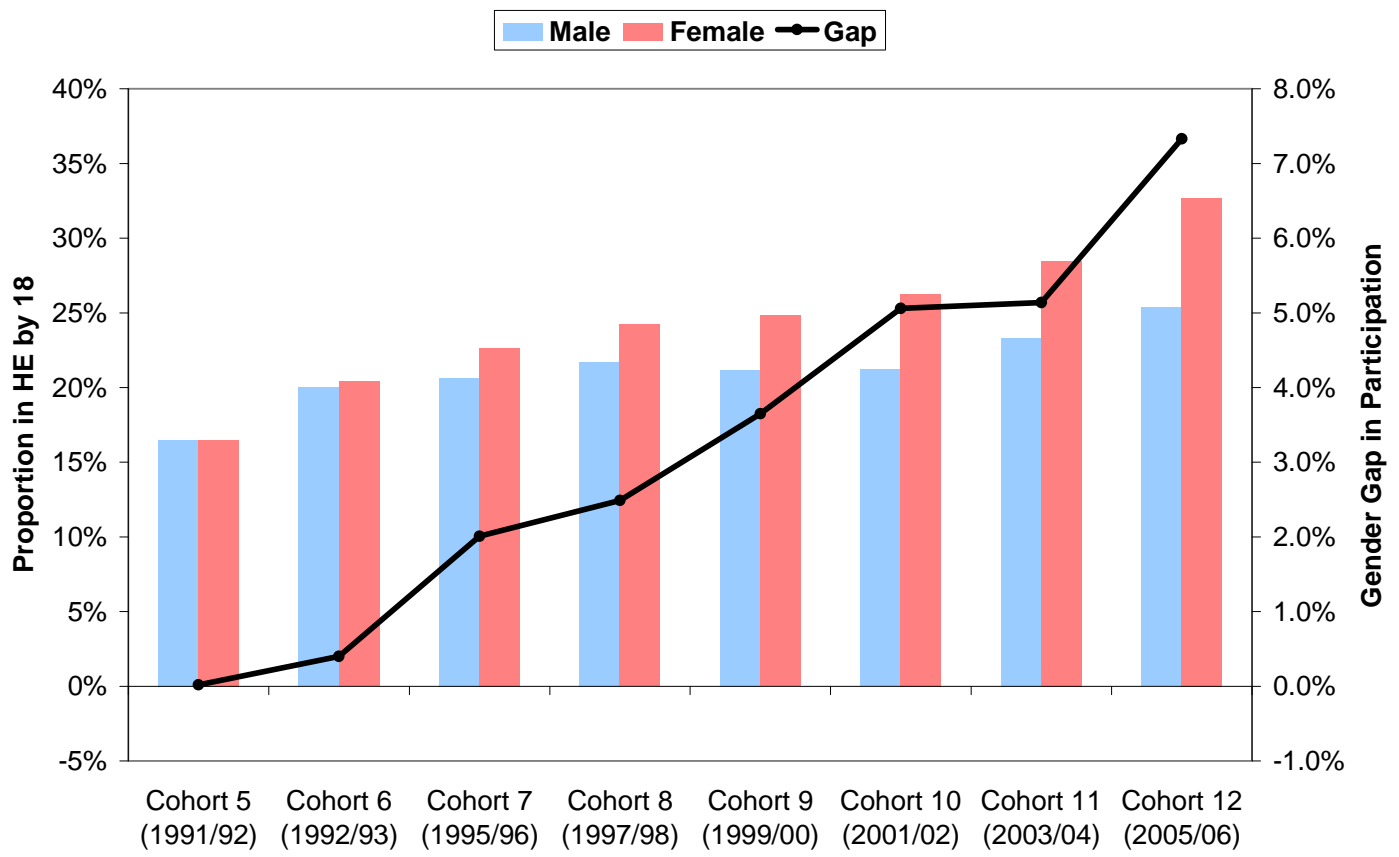

42. Although in terms of raw participation rates women caught up with men in the early 1990s, they were still less likely to progress into HE once prior attainment was controlled for. By the late 1990s, as women continued to increase their participation rates, the gender effect turned insignificant after controlling for prior attainment.

43. This is shown in the graph below which, for each YCS cohort, provides the odds ratios of being in $\mathrm{HE}$ for women compared to men, after controlling for prior attainment. Odds ratios are equal to 1 if there is gender parity in HE participation. Odds ratios smaller than one indicate that women are less likely to be in HE than men, despite their higher prior attainment. And odds ratios larger than 1 would suggest that women are more likely to be in HE than men with similar levels of prior attainment. The graph also shows confidence intervals. If these include the value of 1 , then the gender gap in participation is said to be insignificant. 
Figure 10: Odds ratios of being in HE at age 18 for women compared to men, controlling for prior attainment, YCS Cohorts 4 to 12

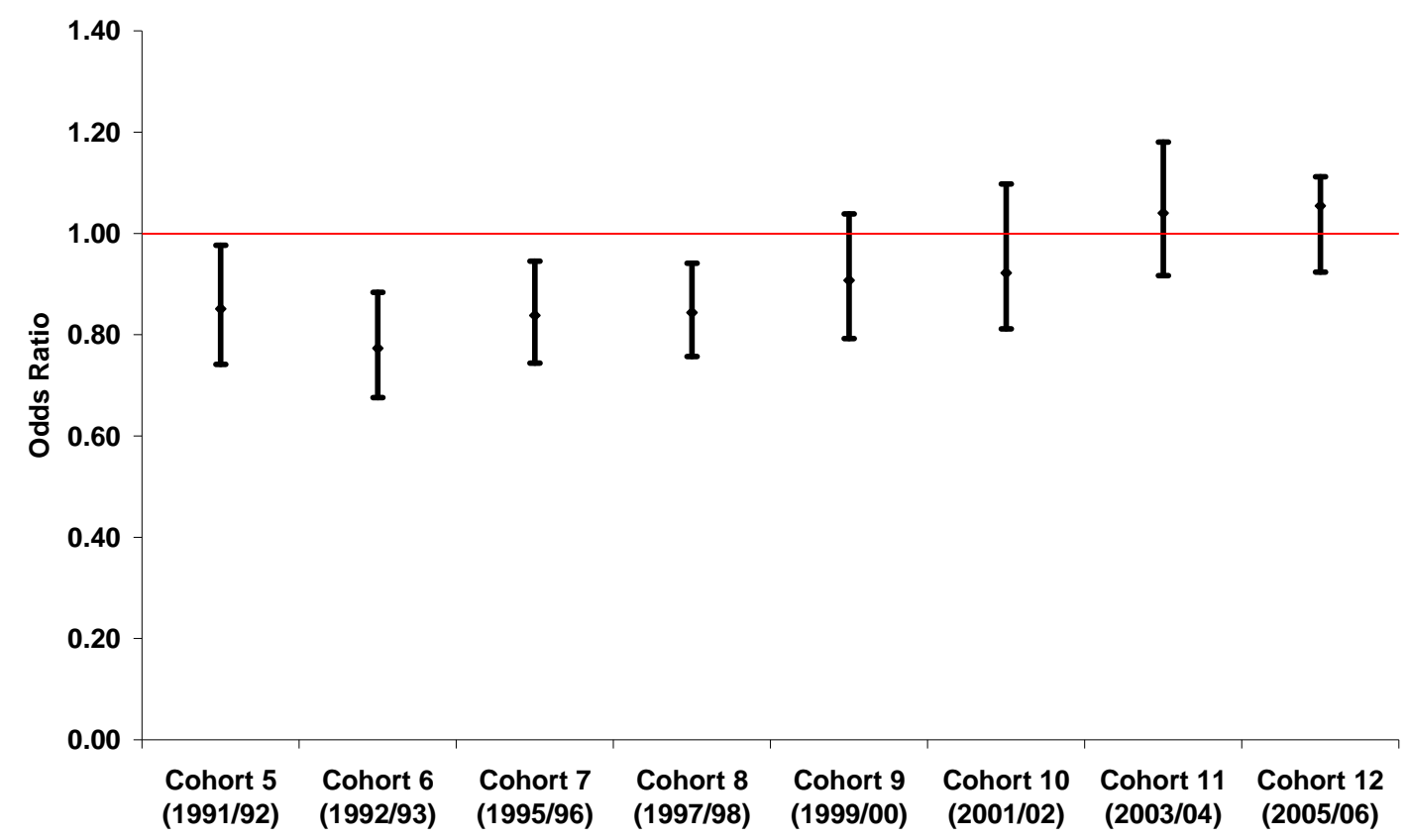

44. Although we have argued in the previous section that the latest data suggests that prior attainment can explain the totality of the gap in HE participation between men and women, the momentum shown in the above analysis suggests that the relationship between gender, prior attainment and HE participation should be kept under close scrutiny in the future to verify whether significant gaps (over and above prior attainment) might arise over time.

\section{Gender Gaps, compared to Social Class and Ethnicity Gaps}

45. Although gender gaps in HE participation are large, gaps in participation between different ethnic groups and between people from lower and higher socio-economic backgrounds: (i) tend to be larger and (ii) remain significant after controlling for prior attainment - although the socio-economic/FSM gap at the point of entry to higher education is also small once prior attainment is controlled for.

46. The following two diagrams show how "raw" participation rates differ for: males v. females; White v. ethnic minority groups; and lower NS-SEC v. higher NS-SEC groups (FSM v. non-FSM for the linked data). ${ }^{28}$

\footnotetext{
${ }^{28}$ The figures for participation by NS-SEC differ from the Department's Full-time Young Participation by Socio-Economic Class (FYPSEC) measure. The latest available FYPSEC data (for 2005/06) suggests that the participation rates stood at $43.3 \%$ for the three higher socio-economic classes, and at $19.9 \%$ for the lower socio-economic classes. The differences stem from the fact that FYPSEC: (i) only covers full-time study; (ii) also includes 20 year olds; (iii) is not available for 2006/07. In addition, the YCS overestimates participation of all groups, as mentioned previously. For more detail about FYPSEC, see Kelly and Cook (2007).
} 
Figure 11: Raw YCS participation gaps by age 19 - English-domiciled young people not in independent schools in Year 11

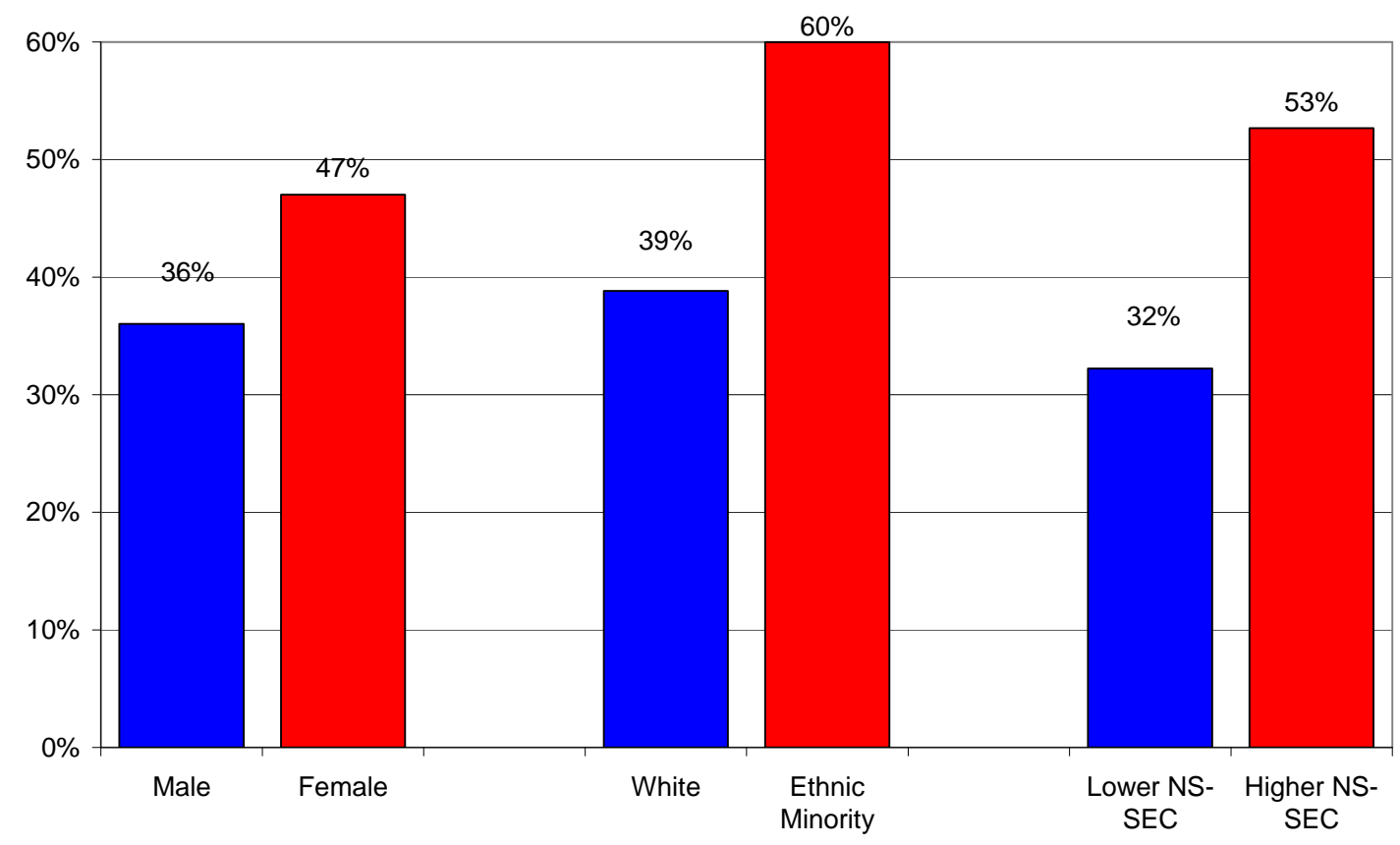

Figure 12: Raw linked administrative data participation gaps by age 19 English-domiciled young people not in independent schools in Year 11

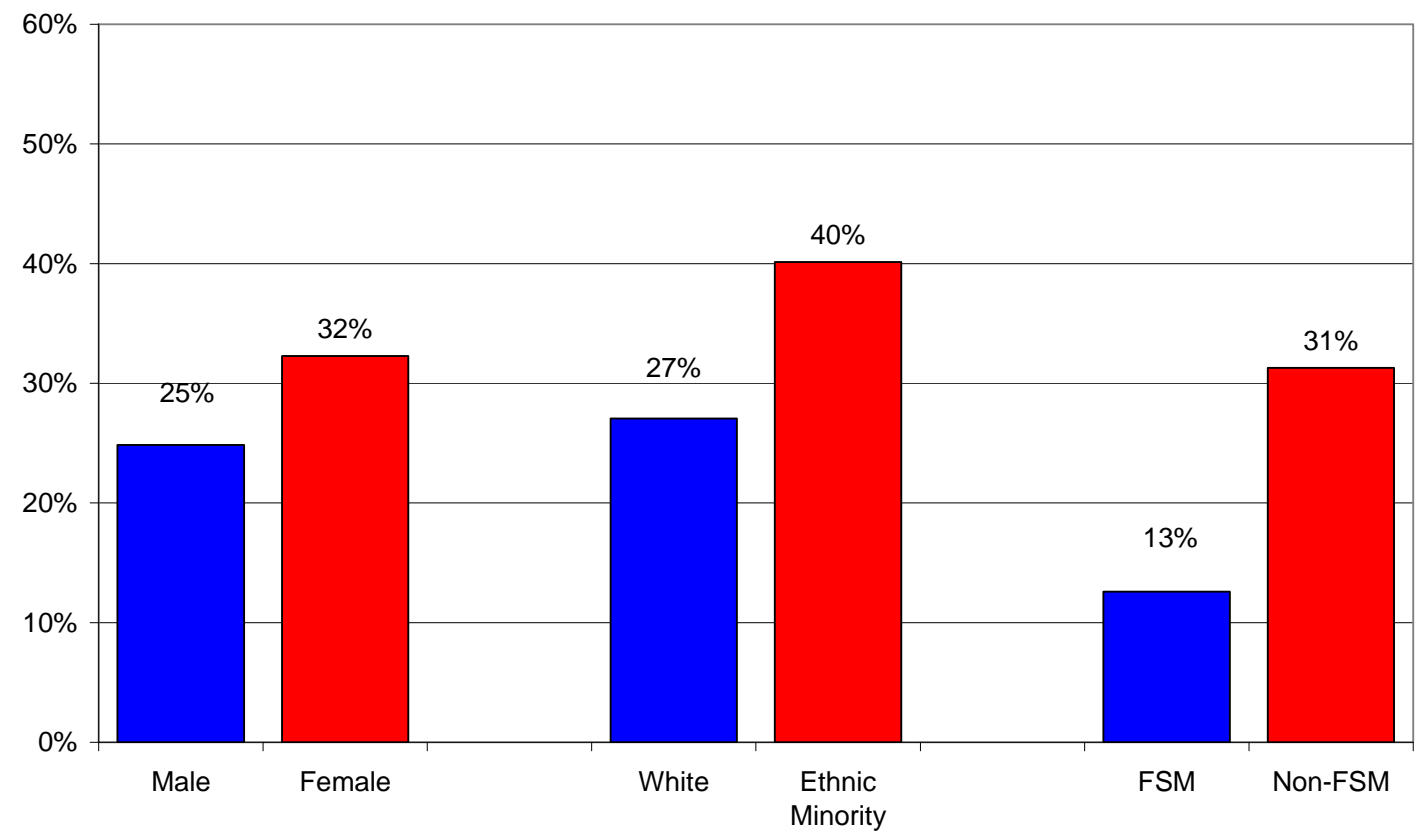


47. Although we are not comparing exactly the same thing on the YCS and on the linked administrative data ${ }^{29}$, both datasets do suggest that the HE participation gaps between deprived and non-deprived pupils are much larger than the gender gap. Similarly, the participation gaps between young people from White and non-White backgrounds are nearly twice as large as those between young men and women.

48. The previous graphs show simple, dichotomous gaps. But the inequalities are cumulative, in the sense that if you are White, male and have been on FSM, your participation rate by age 19 is considerably lower than if you had been from a minority ethnic group, female, and not on FSM. In fact, the latter are eight and a half times more likely to be in HE by 19 than the former:

Figure 13: "Cumulative" disadvantage: in HE by 19 for interactions of Ethnicity, FSM status at age 15 and Gender - English-domiciled young people not in independent schools in Year 11 (linked administrative data)

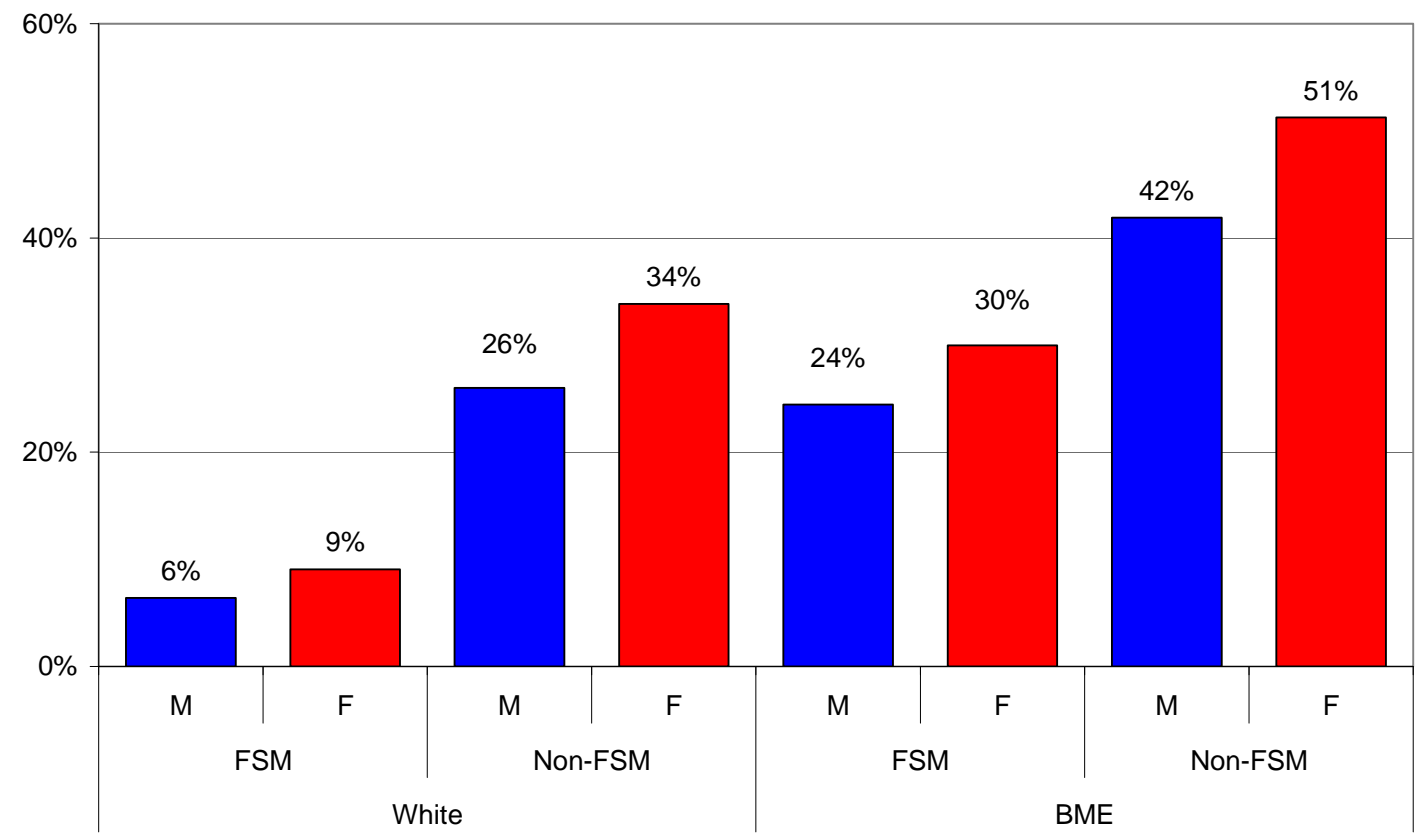

49. The linked data now also allows us to look at ethnicity in more detail (rather than the simple White/non-White dichotomy forced upon us by the small sample sizes of the YCS). Although the low participation rates of White, working class boys is now well publicised, the picture is even worse for Black Caribbean and Black Other boys (and girls, for that matter). ${ }^{30}$

\footnotetext{
${ }^{29}$ As a reminder: on the linked data, we do not include HE in FE, whereas in the YCS we do. Also: on the YCS, we compare participation rates between different socio-economic classes, whereas on the linked administrative data we are looking at participation rates by FSM status. ${ }^{30}$ Connor et al (2004) used aggregate HESA, ILR and Census 2001 data to derive HEIPR rates for the 17-19 and 17-30 age groups, broken down by broad ethnicity grouping. They found that, despite the HEIPR 17-19 being lower for the Black group, their position improves when looking at the HEIPR 17-30, where they have one of the highest participation rates (see tables 4.1 as well as A1 in Appendix one in their publication). Looking at the 17-30 age group, even the Black Caribbean and Black Other groups have higher participation rates, for both males and females, than the White group - suggesting that young people from a Black background enter HE at a later age than young people from White backgrounds.
} 
Figure 14: Gender gaps in HE participation by age 19, by detailed ethnicity English-domiciled young people not in independent schools in Year 11

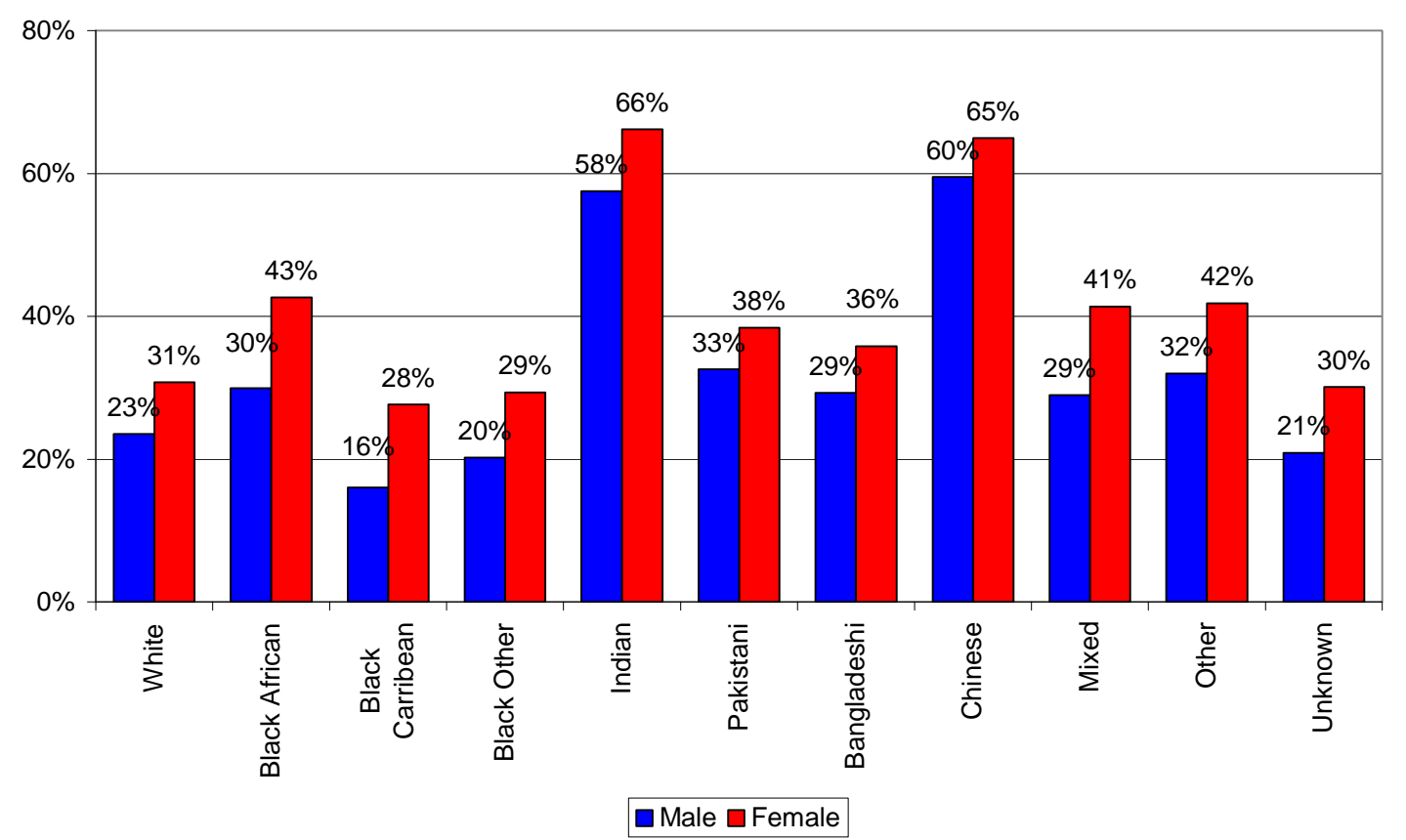

50. Finally, not only are the ethnicity and FSM gaps larger than the gender gap, they also do not disappear entirely after controlling for prior attainment (although the majority of the FSM gap can, in fact, be explained by prior attainment). In the following two diagrams, we have ranked young people into 15 groups according to their GCSE attainment ${ }^{31}$. We then compare participation by ethnicity and FSM within each of these "fifteenths" of GCSE attainment.

${ }^{31}$ Uncapped point scores - excluding those with missing GCSE attainment. 
Figure 15: In HE by 19, by "Fifteenth" of GCSE attainment and Ethnicity English-domiciled young people not in independent schools in Year $11^{32}$

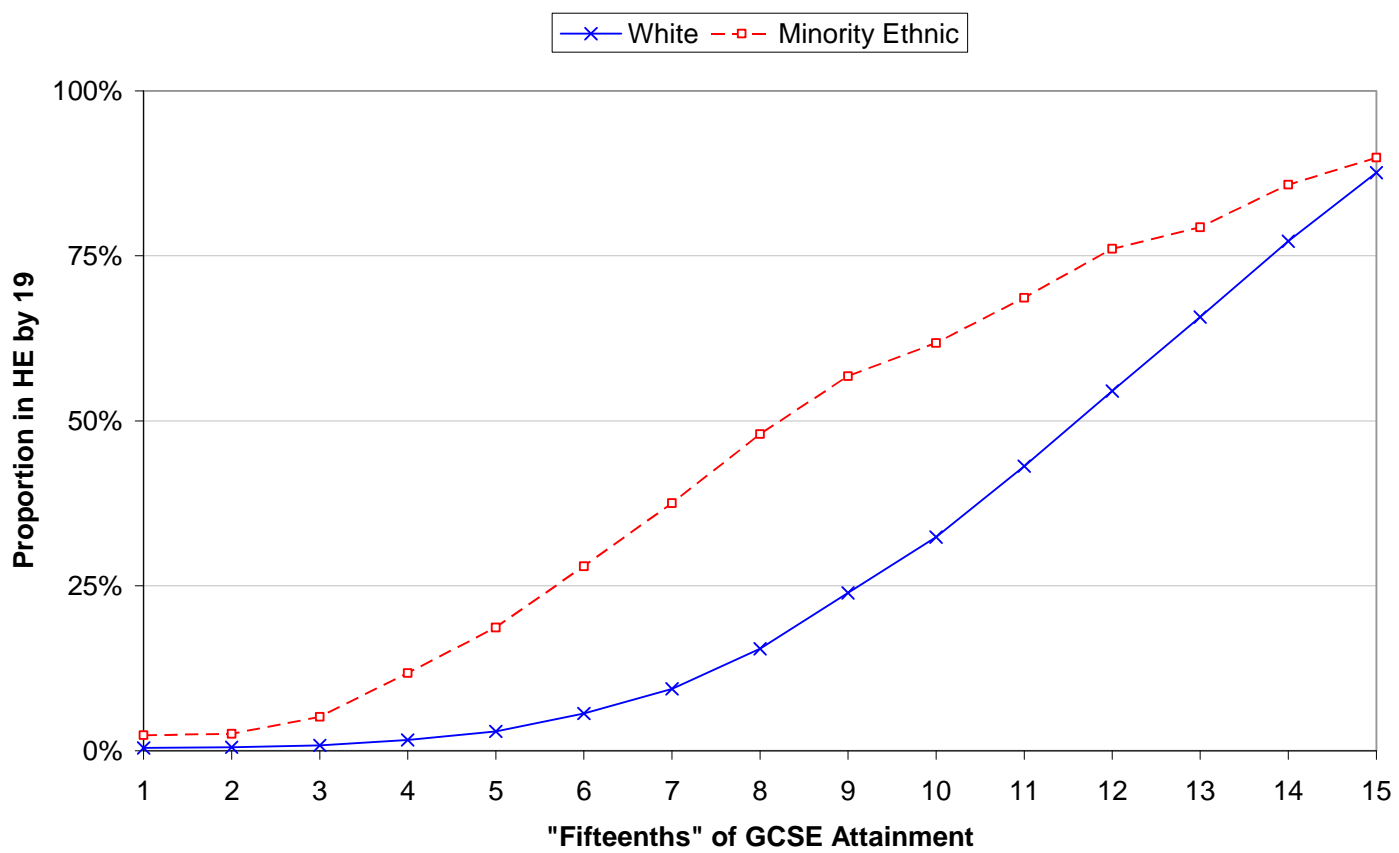

Figure 16: In HE by 19, by "Fifteenth" of GCSE attainment and FSM status at age 15 - English-domiciled young people not in independent schools in Year $11^{33}$

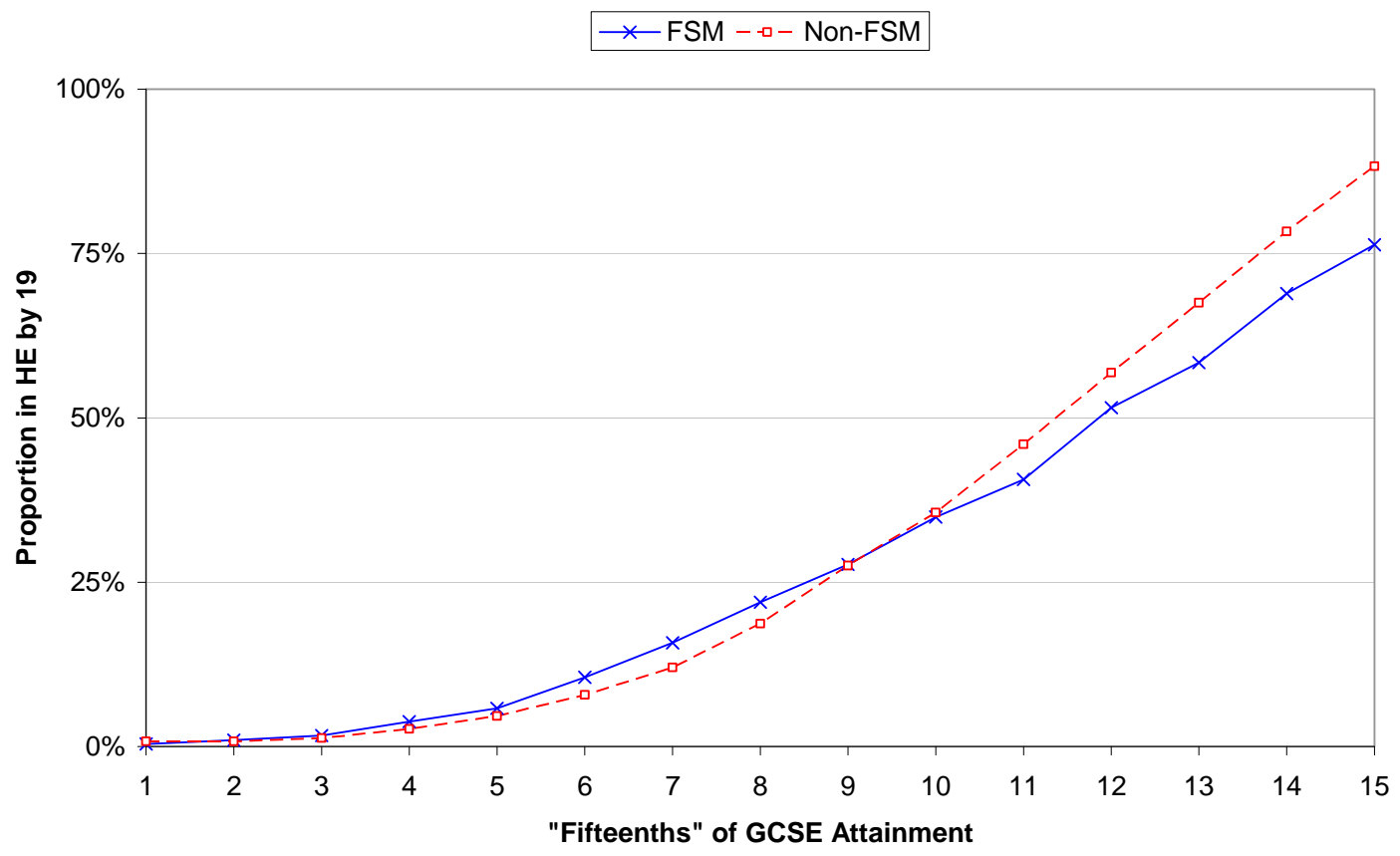

${ }^{32}$ See Annex 6 for the number of cases in each quantile, by ethnicity.

${ }^{33}$ See Annex 6 for the number of cases in each quantile, by FSM status. 
51. As these graphs show, after controlling for prior attainment: (i) minority ethnic groups are still significantly more likely to participate in higher education than their white peers (particularly towards the middle of the GCSE attainment ranking); (ii) FSM students towards the bottom of the GCSE distribution appear to be more likely, whereas those towards the high end of the attainment spectrum are less likely to, participate in HE by 19 compared to their non-FSM peers.

52. The FSM effect is not as overwhelming as the ethnicity effect, and so deserves further investigation. As we shall see later, when we discuss our regression results, the FSM gap does remain significant and negative after controlling for prior attainment as well as other student characteristics. We confirmed this finding by rerunning our regressions using $\mathrm{IDACl}^{34}$ instead of FSM to control for deprivation: in every single regression, the coefficients on the variables controlling for the $25 \%$ most and $25 \%$ second most deprived areas were negative and significant.

53. It is worth pointing out, however, that the FSM effect is small. In terms of the number of people affected, if we assumed that, in the diagram above, young people on FSM in the top six "fifteenths" had participation rates similar to those of the non-FSM pupils, then an additional 700 FSM youngsters would be participating in HE by age 19 , adding 0.9 percentage points to the participation rate of young people on FSM.

54. The fact that ethnicity and FSM status are significant in explaining participation in HE over and above the effect of prior attainment is confirmed by econometric analysis. ${ }^{35}$ We re-ran all the regression from section IV, but now also including controls for FSM status as well as for the broad ethnic groupings "Black", "Asian", "Chinese", "Mixed" and "Other/Unknown". All regression results are attached in Annex 3.

55. In all of our regressions: (i) the effect of FSM on the likelihood of participation status was negative and significant; (ii) the effect of all minority ethnic group controls were positive and significant; and (iii) the effect of gender was, as before, ambiguous and insignificant at the $5 \%$ level in about a third of our regressions (and insignificant at the $1 \%$ level in half of our regressions).

\footnotetext{
${ }^{34} \mathrm{IDACl}$ is the Income Deprivation Affecting Children Index. It is a supplementary index to the Indices of Multiple Deprivation and it measures the proportion of children under the age of 16 in an area living in low income households. IDACI codes are calculated at the Super Output Level and range from 0.00 (least deprived) to 1.00 (most deprived). For our purposes, we created two dummies to include in our regression analysis: one which controlled for the $25 \%$ most deprived areas; and another which controlled for the $25 \%$ second most deprived areas.

${ }^{35}$ In regressions where only FSM is included alongside prior attainment (i.e. excluding gender and ethnicity), the effect of FSM can be made insignificant. However, this is likely to be because FSM is highly correlated with ethnicity (with ethnic minorities much more likely to be on FSM), and so the high participation rates of ethnic minorities will attenuate the negative FSM effect. In our dataset, and for young people in maintained schools only, 12.1\% of Whites were on FSM, compared to $32.4 \%$ of Blacks, $32.6 \%$ of Asians, $12.2 \%$ of Chinese and $36.9 \%$ of Mixed.
} 
56. To get a sense of the relative magnitudes of the effects of gender, FSM status, ethnicity and prior attainment, we can take one of our models ${ }^{36}$ and use it to predict the likelihood of being in HE by 19 for different types of students. Starting with an "average" student with average GCSE attainment and controlling for all else (including prior attainment), the model we picked predicted that the likelihood of participation in HE by 19 :

- $\quad$ Fell by 3.5 percentage points if we made our "average" student eligible for FSM.

- $\quad$ Fell by 0.4 percentage points if we changed our student from male to female (but this result was not significant).

- $\quad$ Increased by 18.0 percentage points if we changed our student from White to Black; ${ }^{37}$

- $\quad$ Increased by 25.4 percentage points if we changed our student from White to Asian;

- $\quad$ Increased by 22.7 percentage points if we changed our student from White to Chinese; and

- $\quad$ Increased by 2.3 percentage points if we increased our student's GCSE attainment by just one point (i.e. one grade increase in one GCSE subject).

57. The above example goes to illustrate the strong effect ethnicity plays, over and above prior attainment, on the likelihood of participating in HE. The example also shows how the effect of FSM status, although negative, is quite small, particularly in comparison to the impact of prior attainment.

58. Before we conclude, it is worth pointing that similar regressions on the YCS (although using socio-economic class rather than FSM) produced very similar results (see Annex 4). In all our models, the effect of ethnicity was positive and highly significant, and the effect of belonging to a lower socio-economic class was negative and highly significant. The effect of gender, by contrast, was significant at the $5 \%$ level in only four of our 18 models - and, where it was, its effect was considerably smaller than the FSM and ethnicity effects.

\footnotetext{
${ }^{36}$ We took model 40 , for no particular reason, except that it contained a simple, linear control for GCSE attainment and predicted HE by 19. Although the exact predicted probabilities quoted here may change slightly depending upon the model we use, the order of relative magnitudes will not.

${ }^{37}$ This may seem counterintuitive, considering the raw participation gaps presented in Figure 14 , however these results control for prior attainment. Young people from a Black background have much lower prior attainment than young people from a White background. However, given this prior attainment, they are more likely to participate in HE than their White peers with similar levels of prior attainment.
} 


\section{Conclusion}

59. The rise in participation of women over the past few decades has been phenomenal and is, without a doubt, one of the great success stories of Higher Education in England. Paradoxically, however, this rise in female participation has made the performance of males look relatively dismal, and concerns have arisen about the increasing gap in participation between men and women. The latest data for England show that $32 \%$ of young women in maintained schools are in HE by age 19 , compared to $25 \%$ of young men in maintained schools - a gap of 7 percentage points.

60. In this paper, we have shown that, once prior attainment is controlled for, the gender gap in HE participation disappears. In other words: the gender gap in HE participation is narrowly related to the gender gap in prior attainment. This is not to say that the gender gap in HE participation does not exist, nor that it isn't large. But our analysis suggests that no additional gender effect appears at the point of entry to Higher Education and, hence, that efforts to reduce the gender gap in HE participation are best aimed at increasing the relative attainment of young men.

61. We have said that the gender gap in HE participation is closely related to the gender gap in prior attainment. This is not necessarily to say, however, that the gender gap in HE participation is caused by gaps in prior attainment. Our statistical models did not allow us to disentangle the direction of causation, but it would be perfectly possible that boys disengage with the educational system at a very early age, and perform very poorly at their GCSEs precisely because they decided a long time ago that they were going to drop out of school at the age of 16 and not go on to HE! Therefore, to echo a recent paper by the Scottish Funding Council on "Gender in Scottish Education":

HE does have a role in challenging and addressing the assumptions and prejudices that lead to some aspects of the pattern. HE should open and change minds rather than simply act as a passive transmitter of the received assumptions on gender.

62. A discussion of gender gaps in HE participation often ends with the question of: does it actually matter? The argument being that, regardless of how much better women perform than men in education, the latter still do far better in the labour market despite the Equal Pay Act 1970 and other Government efforts to reduce the pay gap. A plethora of research has been carried out on this issue, but a recent study looking at data which followed UK university graduates for 42 months following their graduation in 1995, found that the gender wage gap stood at $12.6 \%$ (in favour of men) ${ }^{38}$ It would seem strange, however, to justify differences in education

\footnotetext{
${ }^{38}$ Chevalier (2006). Most of this gender gap (84\%) could be accounted for by differences in education, occupation and expectations. The single most important individual component of the gap was found to be difference about career break expectations, which alone accounted for 10 percent of the gender wage gap.
} 
achievement as compensation for other inequalities - not least because the benefits of learning and Higher Education extend beyond the mere immediate, pecuniary gains.

63. In addition, if the Leitch ambition of making the UK a world leader in skills and exceeding $40 \%$ of adults qualified to level 4 and above by 2020 , up from $29 \%$ in 2005 , is to be achieved, then the participation of men in HE is going to play an absolutely crucial role. As we pointed out in the background section of this paper, the current HEIPR for women stands at $48 \%$, that for men at $38 \%$. So increasing the participation rates of men to levels similar to those of women would bring us close to increasing participation in higher education towards 50\%.

64. So the gender gap in HE participation does matter and, although it can currently be "explained" by prior attainment, the gap continues to widen. For these reasons, it is advisable that the gap continues to be monitored closely and that efforts to raise aspirations and attainment be sustained.

65. The paper also looked at gaps in HE participation between young people from different ethnic groups and from different socio-economic backgrounds. It was found that, in these cases, the gaps (in percentage point terms) were larger than the gender gap, and also they did not disappear entirely after controlling for prior attainment. In fact, in the case of ethnicity, it was overwhelmingly clear the young people from non-White backgrounds were much more likely to participate in HE than their White peers with similar prior attainment.

66. In the case of FSM, we argued that, although we could still find a robust, negative and statistically significant effect - this effect was small, particularly if compared to the impact of prior attainment. In addition, we found that only a relatively small number of pupils on FSM were affected. 


\section{References}

- Chevalier A. (2006): "Education, Occupation and Career Expectations: Determinants of the Gender Pay Gap for UK Graduates", Centre for the Economics of Education Working Paper No. CEEDP0069.

- Connolly, P. (2006): "Keeping a sense of proportion but losing all perspective: A critique of Gorard's notion of the 'politician's error", British Journal of Educational Studies", 54 (1), 73-88.

- Connor, H., C. Tyers, T. Modood and J. Hillage (2004): "Why the Difference? A Closer Look at Higher Education Minority Ethnic Students and Graduates", DfES Research Report No 552.

- Delamont, S. (2006): "Gender and Higher Education" in C. Skelton, B. Francis and L. Smulyan (eds.): "Gender and Education", Sage Publications, London.

- DfES (2006): "Participation in Education, Training and Employment by 16-18 Year Olds in England: 2004 and 2005", SFR 21/2006.

- DfES (2007): "Participation Rates in Higher Education: Academic Years 1999/2000 2005/2006 (Provisional)", SFR 10/2007.

- DfES (2007): "Gender and Education: the evidence on pupils in England".

- Dyhouse, C. (2006): "Students: A Gendered History", Routledge, Abingdon.

- Gorard, S. (1999): "Keeping a sense of proportion: the 'politician's error' in analysing school outcomes", British Journal of Educational Studies", 47 (3), 235-246.

- HEFCW (2007): "Participation Rates for Welsh Students in Higher Education within the UK during 2004/05", W07/08HE.

- Kelly, K. and S. Cook (2007): "Full-time Young Participation by Socio-Economic Class: A New Widening Participation Measure in Higher Education", DfES Research Report RR806.

- OECD (2007): "Education at a Glance".

- Scottish Executive (2007): "The Age Participation Index for Scotland 2005-06", Statistics Publication Notice, Lifelong Learning Series.

- UCAS (2007): "Missed Opportunities - Non-Placed Applicants (NPAs) in the UCAS Data". 


\section{Annex 1: YCS Cohort 12 Regression Results: Gender}

\section{YCS Cohort 12 - HE by 18 - Gender}

\begin{tabular}{|c|c|c|c|c|c|c|}
\hline & Model 1 & Model 2 & Model 3 & Model 4 & Model 5 & Model 6 \\
\hline Female & $0.0936^{\star}$ & $0.0936^{*}$ & 0.0796 & 0.0707 & 0.0674 & 0.0600 \\
\hline Uncapped GCSE & $0.0451^{* \star \star}$ & $0.0558^{\star \star \star}$ & $-0.0391^{* *}$ & & & \\
\hline Uncapped GCSE Squared & & -0.000107 & $0.00212^{x x}$ & & & \\
\hline Uncapped GCSE Cubed & & & $-0.0000152^{\star \star \star}$ & & & \\
\hline Average GCSE & & & & $0.589^{\star \star \star}$ & 0.193 & $-0.739^{\star \star \star}$ \\
\hline Average GCSE Squared & & & & & $0.0417^{* *}$ & $0.301^{* \star *}$ \\
\hline Average GCSE Cubed & & & & & & $-0.0207^{\star \star \star}$ \\
\hline Constant & $-2.754^{\star \star \star}$ & $-2.994^{\star \star \star}$ & $-1.912^{* * \pi}$ & $-3.407^{\star \star \star x}$ & $-2.541^{\star \star \star}$ & $-1.710^{\star \star \star}$ \\
\hline
\end{tabular}

${ }^{*} p<0.05,{ }^{* *} p<0.01,{ }^{* * *} p<0.001$

\section{YCS Cohort 12 - HE by 19 - Gender}

\begin{tabular}{|c|c|c|c|c|c|c|}
\hline & Model 7 & Model 8 & Model 9 & Model 10 & Model 11 & Model 12 \\
\hline Female & $0.119^{*}$ & $0.117^{\star}$ & 0.105 & 0.0870 & 0.0814 & 0.0780 \\
\hline Uncapped GCSE & $0.0462^{\star \star x}$ & $0.0252^{*}$ & -0.0344 & & & \\
\hline Uncapped GCSE Squared & & 0.000235 & $0.00185^{\star \star \star}$ & & & \\
\hline Uncapped GCSE Cubed & & & $-0.0000123^{\star \star \star}$ & & & \\
\hline Average GCSE & & & & $0.579^{\star \star \star x}$ & -0.0630 & -0.346 \\
\hline Average GCSE Squared & & & & & $0.0745^{\star \star \star}$ & $0.162^{*}$ \\
\hline Average GCSE Cubed & & & & & & -0.00762 \\
\hline Constant & $-2.383^{\star \star \star}$ & $-1.977^{\star \star \star}$ & $-1.442^{\text {**x }}$ & $-2.913^{\text {k丈 }}$ & $-1.668^{\star \star \star}$ & $-1.457^{\star \star \star \star}$ \\
\hline
\end{tabular}

${ }^{*} p<0.05,{ }^{* *} p<0.01,{ }^{* * *} p<0.001$ 


\section{Annex 2: Linked Administrative Data Regression Results: Gender}

\section{Linked Administrative Data - HE by 18 - Gender}

\begin{tabular}{|c|c|c|c|c|c|c|c|c|c|}
\hline & Model 13 & Model 14 & Model 15 & Model 16 & Model 17 & Model 18 & Model 19 & Model 20 & Model 21 \\
\hline Female & -0.00182 & -0.00115 & -0.00274 & $0.0181^{\star \star \star}$ & $0.0118^{*}$ & $0.00975^{\star}$ & $0.0170^{\star \star \star}$ & -0.00923 & $-0.0150^{\star *}$ \\
\hline Capped GCSE & $0.0909^{\star \star \star}$ & $0.147^{\star \star \star}$ & $-0.120^{\star \star \star}$ & & & & & & \\
\hline Capped GCSE Missing & $2.357^{\star \star \star}$ & $3.558^{\star \star \star}$ & $0.392^{\star \star \star}$ & & & & & & \\
\hline Capped GCSE Squared & & $-0.000623^{\star * \star}$ & $0.00633^{\star \star \star}$ & & & & & & \\
\hline Capped GCSE Cubed & & & $-0.0000569^{\star \star \star}$ & & & & & & \\
\hline Uncapped GCSE & & & & $0.0587^{* \star *}$ & $0.130^{\star \star \star}$ & $0.0292^{\star \star \star}$ & & & \\
\hline Uncapped GCSE Missing & & & & $1.412^{\star \star \star}$ & $3.253^{\star \star \star}$ & $1.556^{\star \star \star}$ & & & \\
\hline Uncapped GCSE Squared & & & & & $-0.000659^{\star \star \star}$ & $0.00123^{\star \star \star}$ & & & \\
\hline Uncapped GCSE Cubed & & & & & & $-0.0000111^{\star \star \star}$ & & & \\
\hline Average GCSE & & & & & & & $0.629^{\star \star \star}$ & $1.851^{\star \star \star}$ & $-0.925^{\star \star \star}$ \\
\hline Average GCSE Missing & & & & & & & $1.606^{\star \star \star}$ & $5.006^{\star \star \star}$ & $0.347^{\star \star \star}$ \\
\hline Average GCSE Squared & & & & & & & & $-0.105^{\star \star \star}$ & $0.423^{\star \star \star}$ \\
\hline Average GCSE Cubed & & & & & & & & & $-0.0322^{\star \star \star}$ \\
\hline Constant & $-4.645^{\star \star \star}$ & $-5.847^{\star \star \star}$ & $-2.680^{\star \star \star}$ & $-3.709^{\star \star \star}$ & $-5.547^{* \star \star}$ & $-3.849^{* \star \star}$ & $-3.971^{\star \star \star}$ & $-7.360^{\star \star \star}$ & $-2.698^{\star \star \star}$ \\
\hline
\end{tabular}

${ }^{*} p<0.05,{ }^{* *} p<0.01,{ }^{* * *} p<0.001$ 
Linked Administrative Data - HE by 19 - Gender

\begin{tabular}{|c|c|c|c|c|c|c|c|c|c|}
\hline & Model 22 & Model 23 & Model 24 & Model 25 & Model 26 & Model 27 & Model 28 & Model 29 & Model 30 \\
\hline Female & $-0.0161^{\star \star \star}$ & $-0.0192^{* \star \star}$ & $-0.0208^{\star \star \star}$ & -0.00258 & -0.00262 & -0.00767 & 0.00227 & $-0.0170^{\star * \star}$ & $-0.0310^{* \star \star}$ \\
\hline Capped GCSE & $0.0977^{* \star \star}$ & $0.0194^{\star \star \star}$ & $-0.0707^{\star \star \star}$ & & & & & & \\
\hline Capped GCSE Missing & $2.643^{\star \star \star}$ & $1.144^{\star * \star}$ & $0.442^{\star \star \star}$ & & & & & & \\
\hline Capped GCSE Squared & & $0.000973^{* \star}$ & $0.00395^{\star \star \star}$ & & & & & & \\
\hline Capped GCSE Cubed & & & $-0.0000289^{* \star *}$ & & & & & & \\
\hline Uncapped GCSE & & & & $0.0653^{\star * \star}$ & $0.0661^{\star \star \star}$ & $-0.0243^{\star \star \star}$ & & & \\
\hline Uncapped GCSE Missing & & & & $1.753^{\star \star \star}$ & $1.770^{\star \star \star}$ & $0.646^{\star \star \star}$ & & & \\
\hline Uncapped GCSE Squared & & & & & -0.00000807 & $0.00210^{\star \star \star}$ & & & \\
\hline Uncapped GCSE Cubed & & & & & & $-0.0000148^{\star \star \star}$ & & & \\
\hline Average GCSE & & & & & & & $0.699^{\star \star \star}$ & $1.421^{\star \star \star}$ & $-0.931^{\star \star \star}$ \\
\hline Average GCSE Missing & & & & & & & $1.987^{\star \star \star}$ & $3.896^{\star \star \star}$ & $0.119^{\star * \star}$ \\
\hline Average GCSE Squared & & & & & & & & $-0.0649^{\star \star \star}$ & $0.390^{\star \star \star}$ \\
\hline Average GCSE Cubed & & & & & & & & & $-0.0275^{\star \star \star}$ \\
\hline Constant & $-4.459^{\star \star \star}$ & $-2.959^{\star * \star}$ & $-2.257^{\star \star \star}$ & $-3.574^{\star * \star}$ & $-3.592^{\star \star \star}$ & $-2.465^{\star \star \star}$ & $-3.890^{\star * \star}$ & $-5.791^{\star \star \star}$ & $-2.008^{\star \star \star}$ \\
\hline
\end{tabular}

${ }^{*} p<0.05,{ }^{* *} p<0.01,{ }^{* \star *} p<0.001$ 
Annex 3: Linked Administrative Data Regression Results: All

\section{Linked Administrative Data - HE by 18 - All}

\begin{tabular}{|c|c|c|c|c|c|c|c|c|c|}
\hline & Model 31 & Model 32 & Model 33 & Model 34 & Model 35 & Model 36 & Model 37 & Model 38 & Model 39 \\
\hline FSM & $-0.169^{\star \star \star}$ & $-0.166^{\star \star \star}$ & $-0.162^{\star \star \star}$ & $-0.219^{\star \star \star}$ & $-0.201^{\star \star \star}$ & $-0.199^{\star \star \star}$ & $-0.298^{\star \star \star}$ & $-0.196^{\star \star \star}$ & $-0.182^{\star \star \star}$ \\
\hline Unknown FSM Status & -0.0604 & -0.0465 & -0.0831 & -0.0405 & -0.0141 & -0.0340 & $-0.537^{\star \star \star}$ & $-0.337^{\star \star \star}$ & $-0.321^{\star \star \star}$ \\
\hline Female & -0.00140 & -0.000868 & -0.00260 & $0.0201^{\star \star \star}$ & $0.0131^{\star *}$ & $0.0111^{*}$ & $0.0180^{\star \star \star}$ & $-0.0105^{*}$ & $-0.0162^{\star \star \star}$ \\
\hline Black & $0.392^{\star \star \star}$ & $0.399^{* \star *}$ & $0.408^{\star * \star}$ & $0.365^{\star * \star}$ & $0.392^{\star \star \star}$ & $0.390^{\star \star \star}$ & $0.357^{\star \star \star}$ & $0.426^{\star \star \star}$ & $0.427^{\star \star \star}$ \\
\hline Asian & $0.630^{\star \star \star}$ & $0.635^{\star \star \star}$ & $0.643^{\star \star \star}$ & $0.605^{\star \star \star}$ & $0.624^{\star \star \star}$ & $0.624^{\star \star \star}$ & $0.626^{\star \star \star}$ & $0.666^{\star \star \star}$ & $0.665^{\star \star \star}$ \\
\hline Other/Unknown Ethnicity & $0.0976^{\star \star \star}$ & $0.101^{\star \star \star}$ & $0.104^{\star \star \star}$ & $0.110^{\star \star \star}$ & $0.116^{\star \star \star}$ & $0.114^{\star \star \star}$ & $0.0915^{\star * \star}$ & $0.0978^{\star \star \star}$ & $0.0984^{\star \star \star}$ \\
\hline Chinese & $0.499^{\star \star \star}$ & $0.507^{\star \star \star}$ & $0.511^{\star \star \star}$ & $0.480^{\star * *}$ & $0.506^{\star \star \star}$ & $0.506^{\star \star \star}$ & $0.507^{\star \star \star}$ & $0.489^{* \star \star}$ & $0.489^{\star \star \star}$ \\
\hline Mixed Ethnicity & $0.468^{\star \star \star}$ & $0.470^{\star \star \star}$ & $0.477^{\star \star \star}$ & $0.397^{\star \star \star}$ & $0.411^{\star \star \star}$ & $0.412^{\star \star \star}$ & $0.433^{\star \star \star}$ & $0.517^{\star \star \star}$ & $0.516^{\star \star \star}$ \\
\hline Capped GCSE & $0.0918^{\star \star \star}$ & $0.149^{* \star \star}$ & $-0.126^{* \star \star}$ & & & & & & \\
\hline Capped GCSE Missing & $2.399^{\star \star \star}$ & $3.640^{\star \star \star}$ & $0.370^{\star \star \star}$ & & & & & & \\
\hline Capped GCSE Squared & & $-0.000642^{* \star \star}$ & $0.00653^{\star \star \star}$ & & & & & & \\
\hline Capped GCSE Cubed & & & $-0.0000586^{\star \star \star}$ & & & & & & \\
\hline Uncapped GCSE & & & & $0.0590^{\star \star \star}$ & $0.133^{\star \star \star}$ & $0.0296^{\star \star \star}$ & & & \\
\hline Uncapped GCSE Missing & & & & $1.437^{\star \star \star}$ & $3.330^{\star \star \star}$ & $1.599^{\star \star \star}$ & & & \\
\hline Uncapped GCSE Squared & & & & & $-0.000676^{\star \star \star}$ & $0.00125^{\text {** }}$ & & & \\
\hline Uncapped GCSE Cubed & & & & & & $-0.0000113^{\star \star \star}$ & & & \\
\hline Average GCSE & & & & & & & $0.631^{\star * \star}$ & $1.878^{\star \star \star}$ & $-0.961^{\star \star \star}$ \\
\hline Average GCSE Missing & & & & & & & $1.660^{\star \star \star}$ & $5.121^{\star \star \star}$ & $0.356^{\star \star \star}$ \\
\hline Average GCSE Squared & & & & & & & & $-0.107^{\star \star \star}$ & $0.434^{\star \star \star}$ \\
\hline Average GCSE Cubed & & & & & & & & & $-0.0330^{\star \star \star}$ \\
\hline Constant & $-4.737^{\star \star \star}$ & $-5.982^{\star * \star}$ & $-2.711^{\star \star \star}$ & $-3.770^{\star \star \star}$ & $-5.671^{\star \star \star}$ & $-3.937^{\star \star \star}$ & $-4.020^{\star \star \star}$ & $-7.507^{\star \star \star}$ & $-2.744^{\star \star \star}$ \\
\hline
\end{tabular}

${ }^{*} p<0.05,{ }^{* *} p<0.01,{ }^{* * *} p<0.001$ 
Linked Administrative Data - HE by 19 - All

\begin{tabular}{|c|c|c|c|c|c|c|c|c|c|}
\hline & Model 40 & Model 41 & Model 42 & Model 43 & Model 44 & Model 45 & Model 46 & Model 47 & Model 48 \\
\hline FSM & $-0.174^{* * *}$ & $-0.179^{* * *}$ & $-0.175^{\star \star \star}$ & $-0.216^{\star \star \star}$ & $-0.215^{\star \star \star}$ & $-0.210^{\star \star \star}$ & $-0.296^{\star \star \star}$ & $-0.224^{* \star \star}$ & $-0.203^{\star \star \star}$ \\
\hline Unknown FSM Status & 0.0600 & 0.00620 & -0.0296 & 0.0602 & 0.0639 & 0.00997 & $-0.478^{* \star \star}$ & $-0.345^{\star \star \star}$ & $-0.324^{\star \star \star \star}$ \\
\hline Female & $-0.0173^{\star \star \star}$ & $-0.0200^{\star \star \star}$ & $-0.0220^{\star \star \star}$ & -0.00183 & -0.00207 & -0.00725 & 0.00189 & $-0.0203^{* \star \star}$ & $-0.0343^{\star \star \star}$ \\
\hline Black & $0.661^{* * *}$ & $0.637^{* * *}$ & $0.654^{* k *}$ & $0.624^{\star \star \star x}$ & $0.627^{\star \star *}$ & $0.632^{* \star *}$ & $0.609^{* * *}$ & $0.687^{* \star *}$ & $0.680^{* \star *}$ \\
\hline Asian & $0.913^{* * \star}$ & $0.897^{* \star *}$ & $0.911^{* * *}$ & $0.879^{* * \star}$ & $0.880^{* * *}$ & $0.887^{\star \star \star}$ & $0.886^{\star * \star}$ & $0.943^{* * *}$ & $0.941^{\star \star \star}$ \\
\hline Other/Unknown Ethnicity & $0.249^{* * *}$ & $0.242^{\star \star \star}$ & $0.246^{* * *}$ & $0.251^{* * *}$ & $0.252^{* * \pi}$ & $0.252^{\star * \star}$ & $0.221^{\star \star \star}$ & $0.235^{* * \pi}$ & $0.235^{* \star *}$ \\
\hline Chinese & $0.794^{* k *}$ & $0.765^{\star * \pi}$ & $0.768^{* * \pi}$ & $0.764^{* * *}$ & $0.767^{* * \pi}$ & $0.764^{\text {*x* }}$ & $0.727^{\star k \pi}$ & $0.722^{* * \pi}$ & $0.713^{* * \pi}$ \\
\hline Mixed Ethnicity & $0.762^{* * \star}$ & $0.740^{* * *}$ & $0.745^{\star \star \star}$ & $0.683^{* * *}$ & $0.686^{* * *}$ & $0.684^{* * \star}$ & $0.711^{\star * \star}$ & $0.800^{* * *}$ & $0.792^{\star \star \star}$ \\
\hline Capped GCSE & $0.101^{* \star \star}$ & $0.0230^{* * *}$ & $-0.0816^{* *}$ & & & & & & \\
\hline Capped GCSE Missing & $2.739^{* * *}$ & $1.248^{\star \star \star}$ & $0.417^{\star \star \star x}$ & & & & & & \\
\hline Capped GCSE Squared & & $0.000961^{\star \star \star}$ & $0.00439^{\star \star \star}$ & & & & & & \\
\hline Capped GCSE Cubed & & & $-0.0000329^{\star \star \star \star}$ & & & & & & \\
\hline Uncapped GCSE & & & & $0.0670^{\star \star \star}$ & $0.0709^{\star \star \star}$ & $-0.0265^{\star \star \star}$ & & & \\
\hline Uncapped GCSE Missing & & & & $1.810^{* * *}$ & $1.900^{* * *}$ & $0.668^{* * *}$ & & & \\
\hline Uncapped GCSE Squared & & & & & $-0.0000404^{\star * \star}$ & $0.00220^{\star \star \star}$ & & & \\
\hline Uncapped GCSE Cubed & & & & & & $-0.0000157^{\star \star \star x}$ & & & \\
\hline Average GCSE & & & & & & & $0.714^{\star * \pi}$ & $1.486^{\star * *}$ & $-0.996^{\star \star \star}$ \\
\hline Average GCSE Missing & & & & & & & $2.080^{\star x *}$ & $4.120^{\star \star \star}$ & $0.138^{* \star \pi}$ \\
\hline Average GCSE Squared & & & & & & & & $-0.0688^{\star \star \star}$ & $0.412^{\star * \star}$ \\
\hline Average GCSE Cubed & & & & & & & & & $-0.0292^{* \star \star}$ \\
\hline Constant & $-4.674^{* * \pi}$ & $-3.172^{* * \pi}$ & $-2.343^{\text {*xx }}$ & $-3.735^{\star * \pi}$ & $-3.826^{* * \pi}$ & $-2.590^{\text {*x/ }}$ & $-4.032^{* \star \star}$ & $-6.099^{* \times \hbar}$ & $-2.115^{* * \hbar}$ \\
\hline
\end{tabular}

${ }^{*} p<0.05,{ }^{* *} p<0.01,{ }^{* * *} p<0.001$ 


\section{Annex 4: YCS Cohort 12 Regression Results: All}

YCS Cohort 12 - HE by 18 - All

\begin{tabular}{|c|c|c|c|c|c|c|}
\hline & Model 49 & Model 50 & Model 51 & Model 52 & Model 53 & Model 54 \\
\hline Female & $0.0914^{*}$ & $0.0910^{*}$ & 0.0774 & 0.0639 & 0.0613 & 0.0545 \\
\hline Minority Ethnic Group & $0.488^{\star \star \star}$ & $0.497^{* \star}$ & $0.502^{\star \star \star}$ & $0.514^{* \star *}$ & $0.500^{\star \star \star}$ & $0.510^{* \star \star}$ \\
\hline Ethnicity Unknown & 0.0829 & 0.0844 & 0.0983 & 0.0987 & 0.104 & 0.107 \\
\hline Ethnicity Unknown & -0.0746 & -0.0598 & -0.0704 & 0.0295 & 0.0188 & 0.0186 \\
\hline NS-SEC: Unknown & $-0.259^{* \star \star}$ & $-0.263^{\star \star \star}$ & $-0.238^{* * *}$ & $-0.202^{* * \star}$ & $-0.184^{* * \star}$ & $-0.180^{\star \star \star}$ \\
\hline Uncapped GCSE & $0.0447^{\star \star \star}$ & $0.0592^{* * 1}$ & $-0.0344^{\star}$ & & & \\
\hline Uncapped GCSE Squared & & -0.000145 & $0.00204^{\star \star \star x}$ & & & \\
\hline Uncapped GCSE Cubed & & & $-0.0000149^{\star \star \star \star}$ & & & \\
\hline Average GCSE & & & & $0.591^{* * /}$ & 0.255 & $-0.713^{\star \star \star}$ \\
\hline Average GCSE Squared & & & & & $0.0354^{\text {** }}$ & $0.302^{* \pi}$ \\
\hline Average GCSE Cubed & & & & & & $-0.0212^{* \star \star}$ \\
\hline Constant & $-2.684^{\star \star \star}$ & $-3.012^{\text {*x }}$ & $-1.946^{\star \star x}$ & $-3.402^{\text {*x }}$ & $-2.671^{\text {*रx }}$ & $-1.793^{* k}$ \\
\hline
\end{tabular}

${ }^{\star} p<0.05,{ }^{* \star} p<0.01,{ }^{* \star *} p<0.001$ 
YCS Cohort 12 - HE by 19 - All

\begin{tabular}{|c|c|c|c|c|c|c|}
\hline & Model 55 & Model 56 & Model 57 & Model 58 & Model 59 & Model 60 \\
\hline Female & $0.119^{*}$ & $0.119^{*}$ & 0.107 & 0.0794 & 0.0757 & 0.0726 \\
\hline Minority Ethnic Group & $0.819^{\alpha \times k}$ & $0.810^{* * \pi}$ & $0.839^{\star \star \pi \kappa}$ & $0.858^{\text {x*t }}$ & $0.850^{\star \star *}$ & $0.864^{\star \star \star}$ \\
\hline Ethnicity Unknown & $0.691^{*}$ & $0.683^{*}$ & $0.674^{*}$ & $0.729^{*}$ & $0.735^{\star \star}$ & $0.741^{* *}$ \\
\hline NS-SEC: Unknown & -0.109 & -0.127 & -0.143 & -0.00920 & -0.0578 & -0.0653 \\
\hline NS-SEC: Lower & $-0.274^{\star \star \star}$ & $-0.262^{* \star \star *}$ & $-0.249^{* *+*}$ & $-0.226^{\star \star \star}$ & $-0.183^{* \star}$ & $-0.184^{* *}$ \\
\hline Uncapped GCSE & $0.0467^{\star \star \star}$ & $0.0303^{*}$ & -0.0338 & & & \\
\hline Uncapped GCSE Squared & & 0.000183 & $0.00190^{* * *}$ & & & \\
\hline Uncapped GCSE Cubed & & & $-0.0000130^{\star \star \star}$ & & & \\
\hline Average GCSE & & & & $0.595^{\star * \star}$ & -0.0202 & -0.402 \\
\hline Average GCSE Squared & & & & & $0.0713^{\star \star \star \star}$ & $0.189^{*}$ \\
\hline Average GCSE Cubed & & & & & & -0.0102 \\
\hline Constant & $-2.392^{\text {**x }}$ & $-2.076^{\text {ז*K }}$ & $-1.500^{\text {*kx }}$ & $-3.005^{\star \star *}$ & $-1.825^{\star \star \star}$ & $-1.541^{\star \star \star}$ \\
\hline
\end{tabular}

${ }^{*} p<0.05,{ }^{* *} p<0.01,{ }^{* * *} p<0.001$ 


\section{Annex 5: Linked Administrative Data Regression Results: All with IDACI}

\section{Linked Administrative Data - HE by 18 - All with IDACI}

\begin{tabular}{|c|c|c|c|c|c|c|c|c|c|}
\hline & Model 61 & Model 62 & Model 63 & Model 64 & Model 65 & Model 66 & Model 67 & Model 68 & Model 69 \\
\hline Most Deprived IDACI Quartile & $-0.165^{\star \star \star}$ & $-0.164^{\star \star \star}$ & $-0.159^{\star \star \star}$ & $-0.225^{* * \pi}$ & $-0.210^{\star \star \star}$ & $-0.206^{\star \star \star}$ & $-0.253^{\star \star \star}$ & $-0.170^{\star \star \star}$ & $-0.158^{\star \star \star \star}$ \\
\hline 2nd Most Deprived IDACI Quartile & $-0.104^{\star \star \star}$ & $-0.106^{\star \star \star}$ & $-0.104^{\star \star \star}$ & $-0.138^{\star \star \star}$ & $-0.134^{\star \star \star}$ & $-0.131^{\star \star \star}$ & $-0.147^{\star * \star}$ & $-0.114^{\star \star \star}$ & $-0.106^{\star \star \star}$ \\
\hline Female & 0.00232 & 0.00289 & 0.00108 & $0.0250^{\star \star \star}$ & $0.0177^{\star \star \star}$ & $0.0156^{\star *}$ & $0.0243^{\star \star \star}$ & -0.00595 & $-0.0119^{*}$ \\
\hline Female & $0.429^{* * \ldots}$ & $0.438^{* * \pi}$ & $0.445^{* * \pi}$ & $0.419^{* k *}$ & $0.444^{* * *}$ & $0.440^{* * *}$ & $0.405^{* k \pi}$ & $0.460^{* * \pi}$ & $0.458^{\star * \pi}$ \\
\hline Black & $0.651^{* * *}$ & $0.657^{* * *}$ & $0.664^{* * *}$ & $0.636^{* * *}$ & $0.655^{* * *}$ & $0.654^{* * *}$ & $0.650^{* * *}$ & $0.685^{* * *}$ & $0.682^{\star \star \star}$ \\
\hline Asian & $0.103^{* * *}$ & $0.107^{* \star *}$ & $0.109^{* * *}$ & $0.118^{* * *}$ & $0.124^{* * *}$ & $0.121^{\star \star \star}$ & $0.0969^{\star \star \star}$ & $0.102^{* \star \star}$ & $0.103^{\star \star \star}$ \\
\hline Other/Unknown Ethnicity & $0.516^{* * *}$ & $0.525^{* * \pi}$ & $0.528^{* * \pi}$ & $0.506^{* k *}$ & $0.531^{\star \star \pi}$ & $0.530^{* * x}$ & $0.521^{\star k *}$ & $0.501^{* k \pi}$ & $0.500^{* k \pi}$ \\
\hline Chinese & $0.506^{* * *}$ & $0.507^{* * *}$ & $0.513^{* * *}$ & $0.451^{* * \pi}$ & $0.463^{* * *}$ & $0.462^{* * *}$ & $0.480^{* * *}$ & $0.549^{* * *}$ & $0.547^{* * *}$ \\
\hline Capped GCSE & $0.0911^{* * *}$ & $0.149^{* \star \star}$ & $-0.125^{\star \star \star}$ & & & & & & \\
\hline Capped GCSE Missing & $2.366^{\star * *}$ & $3.621^{* * \pi}$ & $0.365^{* k \star}$ & & & & & & \\
\hline Capped GCSE Squared & & $-0.000650^{* * *}$ & $0.00649^{* \star \star}$ & & & & & & \\
\hline Capped GCSE Cubed & & & $-0.0000584^{\star \star * \pi}$ & & & & & & \\
\hline Uncapped GCSE & & & & $0.0584^{\star \star \star}$ & $0.132^{\star * \star}$ & $0.0307^{\star \star \star}$ & & & \\
\hline Uncapped GCSE Missing & & & & $1.409^{* \star \star}$ & $3.291^{\star \star \star}$ & $1.596^{\star * \star}$ & & & \\
\hline Uncapped GCSE Squared & & & & & $-0.000671^{\star \star \star}$ & $0.00121^{\text {k*x}}$ & & & \\
\hline Uncapped GCSE Cubed & & & & & & $-0.0000111^{\star \star *}$ & & & \\
\hline Average GCSE & & & & & & & $0.623^{* \star *}$ & $1.872^{\star \star *}$ & $-0.953^{\star \star \star}$ \\
\hline Average GCSE Missing & & & & & & & $1.598^{* * *}$ & $5.072^{* \star *}$ & $0.338^{\star \star \star}$ \\
\hline Average GCSE Squared & & & & & & & & $-0.107^{\star \star \star}$ & $0.431^{\star \star \star}$ \\
\hline Average GCSE Cubed & & & & & & & & & $-0.0329^{\star \star \star x}$ \\
\hline Constant & $-4.672^{\star \star \star}$ & $-5.929^{\star \star \star}$ & $-2.676^{\star \star \star}$ & $-3.695^{\star \star \star}$ & $-5.585^{\star \star \star}$ & $-3.890^{\star \star \star}$ & $-3.937^{\star \star \star}$ & $-7.443^{\star \star \star}$ & $-2.711^{\star \star \star}$ \\
\hline
\end{tabular}

${ }^{*} p<0.05,{ }^{* *} p<0.01,{ }^{* * *} p<0.001$ 
Linked Administrative Data - HE by 19 - All IDACI

\begin{tabular}{|c|c|c|c|c|c|c|c|c|c|}
\hline & Model 70 & Model 71 & Model 72 & Model 73 & Model 74 & Model 75 & Model 76 & Model 77 & Model 78 \\
\hline Most Deprived IDACI Quartile & $-0.208^{\star \star \star}$ & $-0.205^{* \star \star}$ & $-0.201^{\star \star \star}$ & $-0.260^{\star * \star}$ & $-0.259^{\star \star \star}$ & $-0.250^{\star \star \star}$ & $-0.283^{* * \star}$ & $-0.225^{\star * \star}$ & $-0.202^{\star \star \star}$ \\
\hline 2nd Most Deprived IDACI Quartile & $-0.153^{\star \star \star}$ & $-0.147^{\star \star \star}$ & $-0.145^{\star \star \star}$ & $-0.181^{\star \star \star}$ & $-0.181^{\star \star \star}$ & $-0.174^{* * \pi}$ & $-0.187^{\star \star \star}$ & $-0.166^{\star \star \star}$ & $-0.149^{* * *}$ \\
\hline Female & $-0.0116^{*}$ & $-0.0143^{\star *}$ & $-0.0164^{* \star *}$ & 0.00491 & 0.00465 & -0.000698 & $0.0102^{*}$ & $-0.0134^{* *}$ & $-0.0279^{\star \star \star}$ \\
\hline Female & $0.711^{* \star *}$ & $0.685^{* \star \star}$ & $0.701^{* \star \star}$ & $0.688^{* \star \star}$ & $0.691^{* \star *}$ & $0.692^{* \star *}$ & $0.663^{* * \star}$ & $0.733^{* * \pi}$ & $0.720^{\star \star \star}$ \\
\hline Female & $0.945^{\star \star \star}$ & $0.927^{* * *}$ & $0.941^{* \star *}$ & $0.919^{* * *}$ & $0.921^{* * *}$ & $0.926^{* * *}$ & $0.916^{* * *}$ & $0.971^{\star \star \star}$ & $0.965^{\star \star \star}$ \\
\hline Black & $0.258^{\star * \star}$ & $0.250^{* * *}$ & $0.254^{* \star \star}$ & $0.262^{* k *}$ & $0.263^{\star \star \star}$ & $0.262^{\star * \star}$ & $0.229^{\star * \star}$ & $0.242^{* * \star}$ & $0.241^{\star \star \star}$ \\
\hline Asian & $0.818^{\star \star \star}$ & $0.787^{* \times *}$ & $0.789^{\star k \star}$ & $0.795^{* k \pi}$ & $0.798^{\star \star \star \star}$ & $0.792^{\star \star \star}$ & $0.747^{* * \pi}$ & $0.740^{* * \pi}$ & $0.728^{* * \pi}$ \\
\hline Other/Unknown Ethnicity & $0.814^{\star \star \star}$ & $0.788^{* * *}$ & $0.792^{* * \star}$ & $0.749^{\star \star \star}$ & $0.752^{* * *}$ & $0.746^{* * *}$ & $0.767^{\star \star \star}$ & $0.846^{\star * \star}$ & $0.832^{\star \star \star}$ \\
\hline Capped GCSE & $0.0997^{* \star \star}$ & $0.0235^{* * \star}$ & $-0.0804^{* \star *}$ & & & & & & \\
\hline Capped GCSE Missing & $2.706^{* * *}$ & $1.241^{* * *}$ & $0.412^{* * *}$ & & & & & & \\
\hline Capped GCSE Squared & & $0.000943^{* * \star}$ & $0.00434^{\star \star \star}$ & & & & & & \\
\hline Capped GCSE Cubed & & & $-0.0000327^{* \star \star}$ & & & & & & \\
\hline Uncapped GCSE & & & & $0.0662^{\star \star \star}$ & $0.0702^{\star \star \star}$ & $-0.0255^{\star \star \star}$ & & & \\
\hline Uncapped GCSE Missing & & & & $1.784^{* * *}$ & $1.875^{\text {*** }}$ & $0.664^{* * *}$ & & & \\
\hline Uncapped GCSE Squared & & & & & $-0.0000410^{\star * \star}$ & $0.00216^{\star * \star}$ & & & \\
\hline Uncapped GCSE Cubed & & & & & & $-0.0000154^{\star \star \star}$ & & & \\
\hline Average GCSE & & & & & & & $0.704^{* \star \star}$ & $1.474^{\star \star \star}$ & $-0.986^{* * \pi}$ \\
\hline Average GCSE Missing & & & & & & & $2.013^{\star \star \star}$ & $4.053^{* * *}$ & $0.116^{\star \star \star}$ \\
\hline Average GCSE Squared & & & & & & & & $-0.0684^{\star \star \star}$ & $0.409^{\star \star \star}$ \\
\hline Average GCSE Cubed & & & & & & & & & $-0.0290^{\star \star \star}$ \\
\hline Constant & $-4.581^{\star \star \star}$ & $-3.111^{* \star x}$ & $-2.287^{*}$ & $-3.637^{* k \pi}$ & $-3.729^{\star \star * *}$ & $-2.520^{* * \pi}$ & $-3.927^{x+\pi}$ & $-5.996^{\star * \pi}$ & $-2.062^{* * \pi}$ \\
\hline
\end{tabular}

${ }^{*} p<0.05,{ }^{* \star} p<0.01,{ }^{* \star *} p<0.001$ 


\section{Annex 6: Additional Data for Figures 15 and 16}

Figure 15: number of cases in each quantile, by ethnicity

\begin{tabular}{|c|c|c|c|c|c|c|c|c|c|c|c|c|c|c|c|}
\hline GCSE Quantile & 1 & 2 & 3 & 4 & 5 & 6 & 7 & 8 & 9 & 10 & 11 & 12 & 13 & 14 & 15 \\
\hline \# Minority Ethnic & 3,633 & 3,798 & 4,505 & 3,838 & 4,416 & 3,836 & 3,193 & 3,954 & 3,225 & 3,030 & 3,703 & 2,510 & 3,054 & 3,206 & 2,976 \\
\hline \# White & 32,851 & 28,240 & 32,856 & 28,745 & 33,814 & 30,713 & 27,671 & 34,274 & 29,112 & 28,567 & 35,608 & 25,936 & 31,572 & 32,413 & 29,651 \\
\hline
\end{tabular}

Figure 16: number of cases in each quantile, by FSM status

\begin{tabular}{|c|c|c|c|c|c|c|c|c|c|c|c|c|c|c|c|}
\hline GCSE Quantile & 1 & 2 & 3 & 4 & 5 & 6 & 7 & 8 & 9 & 10 & 11 & 12 & 13 & 14 & 15 \\
\hline \# non-FSM & 24,303 & 23,906 & 29,972 & 27,516 & 33,355 & 31,064 & 28,227 & 35,622 & 30,634 & 30,332 & 38,169 & 27,960 & 34,409 & 35,804 & 33,225 \\
\hline \# FSM & 13,489 & 9,716 & 9,245 & 6,715 & 6,727 & 5,218 & 4,117 & 4,407 & 3,227 & 2,733 & 3,000 & 1,825 & 1,858 & 1,531 & 1,065 \\
\hline
\end{tabular}


Ref: DIUS Research Report 0814

(C) Crown Copyright 2008

www.dius.gov.uk/research

Published by the Department for Innovation,

Universities and Skills

Department for Innovation, Universities \& Skills 